\title{
Modeling and Dynamical Behavior of Rotating Composite Shafts with SMA Wires
}

\author{
Yongsheng Ren, Qiyi Dai, Ruijun An, and Youfeng Zhu \\ College of Mechanical and Electronic Engineering, Shandong University of Science and Technology, Qingdao 266510, China \\ Correspondence should be addressed to Yongsheng Ren; renys@sdust.edu.cn
}

Received 7 May 2013; Accepted 22 January 2014; Published 4 March 2014

Academic Editor: Mohammad Elahinia

Copyright (C) 2014 Yongsheng Ren et al. This is an open access article distributed under the Creative Commons Attribution License, which permits unrestricted use, distribution, and reproduction in any medium, provided the original work is properly cited.

A dynamical model is developed for the rotating composite shaft with shape-memory alloy (SMA) wires embedded in. The rotating shaft is represented as a thin-walled composite of circular cross-section with SMA wires embedded parallel to shaft's longitudinal axis. A thermomechanical constitutive equation of SMA proposed by Brinson is employed and the recovery stress of the constrained SMA wires is derived. The equations of motion are derived based on the variational-asymptotical method (VAM) and Hamilton's principle. The partial differential equations of motion are reduced to the ordinary differential equations of motion by using the Galerkin method. The model incorporates the transverse shear, rotary inertia, and anisotropy of composite material. Numerical results of natural frequencies and critical speeds are obtained. It is shown that the natural frequencies of the nonrotating shaft and the critical rotating speed increase as SMA wire fraction and initial strain increase and the increase in natural frequencies becomes more significant as SMA wire fraction increases. The initial strain of SMA wires appears to have marginal effect on dynamical behaviors of the shaft. The actuation performance of SMA wires is found to be closely related to the ply-angle.

\section{Introduction}

Composite materials have found the increased applications for replacement of the conventional metallic materials in the rotating flexible shaft employed for drive shafts of helicopters, steam, and gas turbines. This is likely attributed to high stiffness and strength/weight ratios of composite shaft compared with its metallic counterparts. The development trend in design of light-weight composite shafts is towards higher operating speeds, which gives rise to the problems of high vibration amplitude and stability. Seeking the solution of these problems has caused great research effort [1] in the dynamic of composite rotor.

A review on the literature in this area has shown that composite shafts have high whirling resistance capability and are less susceptible to dynamic instability associated with metallic shafts [2]. Several attempts to develop mathematical models of spinning composite shafts are reported in the literature. These models include the shaft models based on shell theories [3], or beam theories combined with the strain-displacement relations of the shell theories [4], or a thin-walled beam theory [5]. Song et al. [5] developed the composite thin-walled shaft model based on a thinwalled beam theory of Rehfield [6]. This model was used to investigate the natural frequencies and stability of the system subject to the variation of the axial edge load and the lamination angle of the composite layer. However, since Rehfield's formulation is known to be nonasymptotically correct [7], there is no guarantee for consistent accuracy on the results.

SMA composites are a new class of materials that have the ability to change both their stiffness and their elastic properties [8]. SMA composites consist of SMA actuators embedded into a matrix material or in a fiber-reinforced composite. This stiffness modification occurs as a result of thermally induced martensite phase transformation of SMA actuators embedded in composite structures. Several studies have been done on [9-15] combining the advantages of both the composite material and the SMA to build smart composite shafts. Baz and Chen [9] have proposed a smart shaft, which can actively stiffen in response to increased rotational speed or increased amplitudes of vibration. Their results showed activating the Nitinol wires results in reducing the amplitude of its vibration amplitudes by about $50 \%$. 


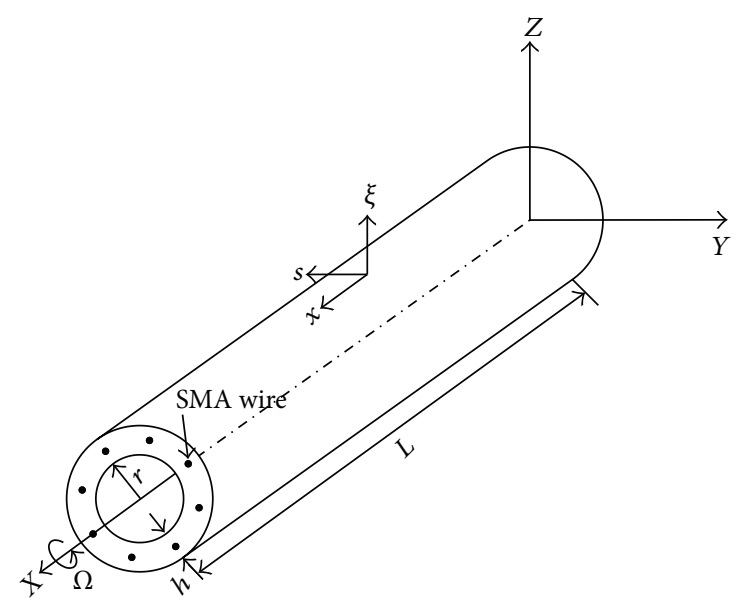

(a) Global view of the shaft

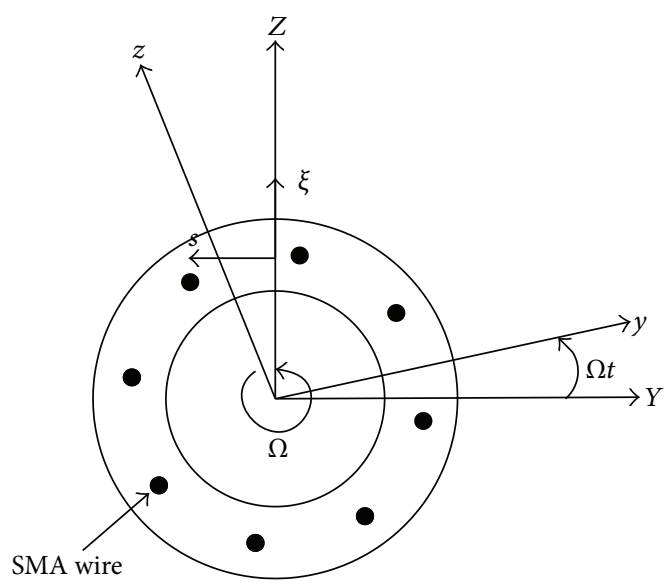

(b) Cross-section of the shaft

FIGURE 1: Schematic drawing of the composite thin-walled beam of a circular cross-section.

Gupta [10] investigated the combined effect of embedding the SMA wires in a rotor shaft and change of support stiffness using the SMA on rotor critical speeds. Sawhney and Jain [11] carried out fabrication and experimental investigations on the fiber-reinforced composite shaft embedded with the SMA wires. Baz and Chen [12] studied the static and thermal characteristics of SMA-reinforced composite drive shafts. They found that the Nitinol wires can play a role in enhancing the torsional stiffness. Tylikowski [13] studied the dynamic stability of globally activated simply supported hybrid shells consisting of symmetrical balanced angle-ply laminated classical plies and symmetrically laminated active plies with axially oriented SMA fibers. Their results indicate that the activation significantly increases the critical value of angular velocity. Tylikowski and Hetnarski [14] analyzed the stability criterion of the shaft equilibrium. The shaft is treated as a thin symmetrically laminated shell containing both the conventional fibers and the activated SMA fibers. The results indicated that the SMA activation significantly increases the stability domains of the shaft. Gupta et al. [15] designed an experimental setup to embed prestrained SMA wires in the fiber-reinforced composite shaft. Experimental results showed a noticeable increase in the natural frequency of the composite shaft due to activation of SMA wires.

In our dynamics study, the rotating shaft is represented as a thin-walled composite of circular cross-section embedded with SMA wires. It is the purpose of the present work to study the effect of increase in stiffness and tension in wires due to phase recovery stresses when wires are activated on the rotor dynamic characteristics such as natural frequencies and the critical speeds. The modeling of the rotating shaft is based on the VAM by Berdichevsky et al. [7]. The thermomechanical constitutive equation of SMA proposed by Brinson [16] is employed to establish the constitutive equation of the SMA reinforced composite shaft. To determine the rotating shaft's dynamical characteristics, the Galerkin approach is carried out here to approximate the motion equations by a system of ordinary differential equations. Based on these approximate equations the dynamical characteristics of the rotating shaft systems are then calculated. Finally, the influence of SMA activation on dynamical behaviors of the rotating composite shaft has been examined.

\section{Theoretical Formulations}

2.1. Coordinate Systems and Basic Assumptions. The composite shaft of length $L$, thickness $h$, and the radius of curvature $r$ rotating with constant rate $\Omega$. As seen in Figure 1, $(x, y, z)$ is the rotating coordinate system, $(X, Y, Z)$ is the inertial coordinate system, and $(x, s, \xi)$ is the local coordinate system. The coordinate systems $(x, y, z)$ and $(X, Y, Z)$ have the common origin $o$ located in the geometric center. It is assumed that at $t=0$, the axes of the two systems coincide.

In our study, the following assumptions are made. (1) The composite shaft is characterized as a slender thin-walled beam [7]; the geometric dimensions are such that $d \ll L, h \ll$ $d, h \ll r ;(2)$ transverse shear effects are considered, where $L, h, r$, and $d$ denote the length, the thickness, the radius of curvature, and the maximum cross-sectional dimension of the cylinder, respectively; (3) the SMA wires are embedded at an interlayer of the shaft and arranged parallel to its longitudinal axis.

2.2. Equations of Motion. Berdichevsky et al. [7] have shown that VAM is an asymptotically correct theory which can be used effectively for the analysis of tubular composite thinwalled. However, VAM does not account for the effects of transverse shear because of which it may generate inaccurate predictions of the rotating composite shaft. In the present work, VAM has been refined to include effects of transverse shear.

The displacement field incorporating shear deformation in the local frame denoted $(x, s, \xi)$ is assumed in the form

$$
\begin{aligned}
u_{1}(x, y, z, t)= & U_{1}(x, t)-y(s) \theta_{y}(x, t) \\
& -z(s) \theta_{z}(x, t)+g(s, x, t),
\end{aligned}
$$




$$
\begin{aligned}
& u_{2}(x, y, z, t)=U_{2}(x, t)-z \phi(x, t), \\
& u_{3}(x, y, z, t)=U_{3}(x, t)+y \phi(x, t),
\end{aligned}
$$

where $U_{1}(x, t), U_{2}(x, t), U_{3}(x, t)$ denote the rigid-body translations along the $x$-, $y$-, and $z$-axes, while $\phi(x, t), \theta_{y}(x, t)$, $\theta_{z}(x, t)$ denote the twist about the $x$-axis and rotations about the $y$ - and $z$-axes, respectively. lows:

The warping functions $g(s, x, t)$ can be assumed as fol-

$$
\begin{aligned}
g(s, x, t)= & G(s) \phi^{\prime}(x, t)+g_{1}(s) U_{1}^{\prime}(x, t) \\
& +g_{2}(s) \theta_{y}^{\prime}(x, t)+g_{3}(s) \theta_{z}^{\prime}(x, t) .
\end{aligned}
$$

In the above equation, the functions $g_{1}(s), g_{2}(s), g_{3}(s)$, $G(s)$ are associated with physical behavior for the axial strain, the bending curvatures, and the torsion twist rate, respectively. The primes in (2) denote differentiation with respect to $x$.

In (1) and (2), the expressions of $\theta_{y}(x, t), \theta_{z}(x, t)$ are in the following form:

$$
\begin{aligned}
& \theta_{y}(x, t)=U_{2}^{\prime}(x, t)-2 \gamma_{z x} \\
& \theta_{z}(x, t)=U_{3}^{\prime}(x, t)-2 \gamma_{y x} .
\end{aligned}
$$

Based on the displacement representations (1), (2), and (3), and using the linear strain-displacement relations [7], while referring to [17], the strain of the composite shaft can be expressed as

$$
\begin{gathered}
\gamma_{x x}=U_{1}^{\prime}(x, t)-y \theta_{y}^{\prime}(x, t)-z \theta_{z}^{\prime}(x, t), \\
2 \gamma_{x s}=\frac{d g}{d s}+r_{n} \phi^{\prime}+\left(U_{2}^{\prime}(x, t)-\theta_{y}(x, t)\right) \frac{d y}{d s} \\
+\left(U_{3}^{\prime}(x, t)-\theta_{z}(x, t)\right) \frac{d z}{d s} \\
2 \gamma_{x \xi}=\left(U_{2}^{\prime}(x, t)-\theta_{y}(x, t)\right) \frac{d z}{d s} \\
-\left(U_{3}^{\prime}(x, t)-\theta_{z}(x, t)\right) \frac{d y}{d s} .
\end{gathered}
$$

The position vector of an arbitrary point on the crosssection of the deformed shaft is $\mathbf{r}=\left(y+u_{2}\right) \mathbf{i}+\left(z+u_{3}\right) \mathbf{j}+$ $\left(x+u_{1}\right) \mathbf{k}$. Here, $\mathbf{i}, \mathbf{j}, \mathbf{k}$ are unit vectors of the coordinate systems $(x, y, z)$. By taking the time derivatives of unit vectors and adopting the assumption of constant rate $W$, the velocity vector of an arbitrary point is $\mathbf{V}=\mathbf{\mathbf { r }}=\left[\dot{u}_{2}-\Omega\left(z+u_{3}\right)\right] \mathbf{i}+$ $\left[\dot{u}_{3}+\Omega\left(y+u_{2}\right)\right] \mathbf{j}+\dot{u}_{1} \mathbf{k}$.

The equations of motion for the rotating composite shaft are derived based on Hamilton's principle, which can be expressed as [18]

$$
\int_{t_{0}}^{t_{1}}(\delta U-\delta T-\delta W) d t=0
$$

where

$$
U=\frac{1}{2} \int_{\tau} \sigma_{i j} \varepsilon_{i j} d s d \xi d x, \quad K=\frac{1}{2} \int_{\tau} \rho(\dot{\mathbf{r}} \cdot \dot{\mathbf{r}}) d s d \xi d x
$$

are the strain energy and the kinetic energy of the composite shaft, respectively.

Here $t_{0}$ and $t_{1}$ are two arbitrary instants of time, $\sigma_{i j}$ and $\varepsilon_{i j}$ are the stress components and the strain components, respectively, $W$ is the virtual work of the external forces, $\rho$ is the mass density, and $\delta$ is the variation operator.

In order to display the elastic coupling between vertical bending and horizontal bending, a special ply-angle distribution referred to as circumferentially uniform stiffnessCUS configuration [19], achieved by skewing angle plies with respect to the longitudinal beam axis meeting the condition $\theta(y)=\theta(-y), \theta(z)=\theta(-z)$, is considered.

By employing Hamilton's principle and taking into account the results with a longitudinal compressive force in [20], which is generated by SMA wires activation, the equations of motion involving CUS configuration in terms of displacements can be written as

$$
\begin{gathered}
-k_{35} \theta_{z}^{\prime \prime}-k_{55}\left(U_{2}^{\prime \prime}-\theta_{y}^{\prime}\right)+\left(N^{\mathrm{SMA}}-N^{\Delta T}\right) U_{2}^{\prime \prime} \\
+b_{1}\left(\ddot{U}_{2}-2 \Omega \dot{U}_{3}-\Omega^{2} U_{2}\right)=0, \\
-k_{46} \theta_{y}^{\prime \prime}-k_{66}\left(U_{3}^{\prime \prime}-\theta_{z}^{\prime}\right)+\left(N^{\mathrm{SMA}}-N^{\Delta T}\right) U_{3}^{\prime \prime} \\
+b_{1}\left(\ddot{U}_{3}+2 \Omega \dot{U}_{2}-\Omega^{2} U_{3}\right)=0, \\
-k_{44} \theta_{y}^{\prime \prime}-k_{46} U_{3}^{\prime \prime}-k_{55}\left(U_{2}^{\prime}-\theta_{y}\right)-b_{4} \ddot{\theta}_{y}=0, \\
-k_{33} \theta_{z}^{\prime \prime}-k_{35} U_{2}^{\prime \prime}-k_{66}\left(U_{3}^{\prime}-\theta_{z}\right)-b_{5} \ddot{\theta}_{z}=0,
\end{gathered}
$$

in which

$$
\begin{gathered}
k_{33}=\oint_{\Gamma}\left(A-\frac{B^{2}}{C}\right) z^{2} d s+\left\{\frac{\left[\oint_{\Gamma}(B / C) z d s\right]^{2}}{\oint_{\Gamma}(1 / C) d s}\right\}, \\
k_{44}=\oint_{\Gamma}\left(A-\frac{B^{2}}{C}\right) y^{2} d s+\left\{\frac{\left[\oint_{\Gamma}(B / C) y d s\right]^{2}}{\oint_{\Gamma}(1 / C) d s}\right\}, \\
k_{35}=-\frac{1}{2} \oint_{\Gamma} B z \frac{d y}{d s} d s, \\
k_{46}=-\frac{1}{2} \oint_{\Gamma} B y \frac{d z}{d s} d s, \\
k_{55}\left[\frac{1}{2} C\left(\frac{d y}{d s}\right)^{2}+D\left(\frac{d z}{d s}\right)^{2}\right] d s, \\
k_{66}=\oint_{\Gamma}\left[\frac{1}{2} C\left(\frac{d z}{d s}\right)^{2}+D\left(\frac{d y}{d s}\right)^{2}\right] d s .
\end{gathered}
$$


Herein,

$$
\begin{gathered}
A=A_{11}-\frac{\left(A_{12}\right)^{2}}{A_{22}}, \quad B=2\left[A_{16}-\frac{A_{12} A_{26}}{A_{22}}\right], \\
C=4\left[A_{66}-\frac{\left(A_{26}\right)^{2}}{A_{22}}\right], \quad D=A_{44}-\frac{\left(A_{45}\right)^{2}}{A_{55}}, \\
A_{i j}=\sum_{k=1}^{N} \bar{Q}_{i j}^{(k)}\left(z_{k}-z_{k-1}\right), \\
(i, j=1,2,6 ; i, j=4,5),
\end{gathered}
$$

where $A_{i j}$ denotes the local stretching stiffness. $\bar{Q}_{i j}^{(k)}$ denotes the element of the transformed stiffness matrix of the $k$ th layer.

In the case of CUS configuration, it can be seen that (7) reveals different elastic couplings which consist of the coupling between flapwise bending and chordwise bending, the coupling between flapwise transverse shear and chordwise bending, and the coupling between chordwise transverse shear and flapwise bending.

And

$$
\overline{\mathbf{Q}}=\mathbf{T Q}(\mathbf{T})^{T},
$$

in which

$$
\begin{gathered}
\mathbf{T}=\left[\begin{array}{ccc}
n^{2} & m^{2} & -2 m n \\
m^{2} & n^{2} & 2 m n \\
m n & -m n & n^{2}-m^{2}
\end{array}\right], \\
\mathbf{Q}=\left[\begin{array}{ccc}
Q_{11} & Q_{12} & 0 \\
Q_{21} & Q_{22} & 0 \\
0 & 0 & Q_{66}
\end{array}\right]
\end{gathered}
$$

and $\mathbf{Q}$ is the stiffness matrix, $n=\cos \theta, m=\sin \theta$, and $\theta$ is the fiber ply-angle.

And

$$
\begin{gathered}
Q_{11}=\frac{E_{1}}{1-v_{12} v_{21}}, \quad Q_{12}=Q_{21}=\frac{v_{12} E_{2}}{1-v_{12} v_{21}}, \\
Q_{22}=\frac{E_{2}}{1-v_{12} v_{21}}, \quad Q_{66}=G_{12} .
\end{gathered}
$$

In addition, the mass terms $b_{4}, b_{5}$, and $b_{6}$ in (7) are expressed as

$$
b_{4}=\iint_{A} \rho y^{2} d A, \quad b_{5}=\iint_{A} \rho z^{2} d A, \quad b_{6}=\iint_{A} \rho y z d A .
$$

The modulus and Poisson's ratio of the shaft can be determined by considering the mixture rule of composition

$$
\begin{aligned}
& E_{1}=E_{1 m}\left(1-V_{s}\right)+E_{s} V_{s}, \\
& E_{2}= \frac{E_{2 m} E_{s}}{E_{2 m} V_{s}+E_{s}\left(1-V_{s}\right)}, \\
& G_{12}= \frac{G_{12 m} G_{s}}{G_{12 m} V_{s}+G_{s}\left(1-V_{s}\right)}, \\
& v_{12}= v_{12 m}\left(1-V_{s}\right)+v_{s} V_{s}, \\
& \frac{v_{12}}{E_{1}}=\frac{v_{21}}{E_{2}},
\end{aligned}
$$

where the subscript $m$ and $s$ denote the composite matrix and SMA wire, respectively, and $V$ is volume fraction.

Herein,

$$
V_{s}=\frac{A_{\text {sma }}}{A_{\text {Total }}}
$$

where $A_{\text {sma }}$, $A_{\text {Total }}$ express the total cross-sectional areas of the embedded SMA wires and the composite shaft, respectively, and

$$
A_{\mathrm{sma}}=\frac{\pi d^{2}}{4} n
$$

where $n$ and $d$ represent the number and diameter of the SMA wires, respectively.

The terms $N^{\text {SMA }}$ and $N^{\Delta T}$ appearing in (7) denote the axial tension due to thermal expansion and SMA wires activation, respectively.

The axial tensions $N^{\mathrm{SMA}}$ and $N^{\Delta T}$ are given by

$$
\begin{aligned}
N^{\Delta T}=2 \pi r \sum_{k=1}^{n}\left(\bar{Q}_{11 k} \bar{\alpha}_{x k}+\bar{Q}_{12 k} \bar{\alpha}_{y k}\right. \\
\\
\left.\quad+\bar{Q}_{16 k} \bar{\alpha}_{x y k}\right) \cdot\left(z_{k}-z_{k-1}\right) \Delta T,
\end{aligned}
$$

where $\bar{\alpha}_{x k}, \bar{\alpha}_{y k}$, and $\bar{\alpha}_{x y k}$ denote the reduced thermal expansion coefficients in the $k$ th layer of composite medium, and

$$
N^{\mathrm{SMA}}=\frac{\pi d^{2}}{4} n \sigma_{r}=A_{\mathrm{sma}} \sigma_{r},
$$

where $\sigma_{r}$ represents the recovery stress which can be determined analytically.

By eliminating from (7) the quantities $k_{55}\left(U_{2}^{\prime \prime}-\theta_{y}^{\prime}\right)$ and $k_{66}\left(U_{3}^{\prime \prime}-\theta_{z}^{\prime}\right)$, using the relations $\theta_{y}(x, t)=U_{2}^{\prime}(x, t)$ and $\theta_{z}(x, t)=U_{3}^{\prime}(x, t)$, the equations of motion for unshearable shaft can be obtained. The results are not presented in this paper for the sake of simplicity.

\section{The Recovery Stress of the Constrained SMA Wires}

Based on the one-dimensional model of SMA proposed by Brinson [16] and assuming all SMA wires are fully 
constrained, the expressions for the recovery stress of SMA wires during heating and cooling can be written as follows, respectively:

(i) during heating,

$$
\sigma_{r}= \begin{cases}\Theta\left(T-T_{0}\right)+\sigma_{0}, & 0 \leq T \leq A_{s}^{\sigma} \\ E(\xi) \varepsilon_{0}-E\left(\xi_{0}\right) \varepsilon_{0}+\Omega(\xi) \xi_{s} & \\ -\Omega\left(\xi_{0}\right) \xi_{s 0}+\Theta\left(T-A_{s}^{\sigma}\right)+\sigma_{1}, & A_{s}^{\sigma} \leq T \leq A_{f}^{\sigma} \\ \Theta\left(T-A_{f}^{\sigma}\right)+\sigma_{2}, & T \geq A_{f}^{\sigma},\end{cases}
$$

(ii) during cooling,

$$
\sigma_{r}= \begin{cases}\Theta\left(T-A_{f}^{\sigma}\right)+\sigma_{2}, & M_{s}^{\sigma} \leq T \leq A_{f}^{\sigma} \\ E(\xi) \varepsilon_{0}-E\left(\xi_{0}\right) \varepsilon_{0}+\Omega(\xi) \xi_{s} & \\ +\Theta\left(T-M_{s}^{\sigma}\right)+\sigma_{3}, & M_{f}^{\sigma} \leq T \leq M_{s}^{\sigma},\end{cases}
$$

where $\xi$ denotes the martensite fraction, $E(\xi)$ denotes the elastic modulus of SMA, $\Theta$ denotes the thermal elastic modulus, $T$ denotes temperature, $T_{0}$ is the reference temperature, and $\Omega(\xi)$ denotes the phase transformation coefficient. The subscript 0 denotes initial state. $A_{s}^{\sigma}$ and $A_{f}^{\sigma}$ denote the start and finish temperatures of Austenite in stress, and $M_{s}^{\sigma}$ and $M_{f}^{\sigma}$ denote the start and finish temperatures of martensite in stress. $\xi_{s}$ is the martensite fraction induced by stress. The first expression in (21a) is used for SMA in the initial martensite state, while the third expression among them is used for SMA in $100 \%$ austenite state, and the second one among them is used for SMA in the phase transformation state from martensite to Austenite.

The transformation processes from martensite to austenite $(M \rightarrow A)$ and from austenite to martensite are given as follows $(A \rightarrow M)$, respectively:

$$
\begin{aligned}
\xi_{M \rightarrow A}= & \frac{\xi_{s 0}}{2}\left\{\cos \left[\frac{\pi}{A_{f}-A_{s}}\left(T-A_{s}-\frac{\sigma^{r}}{C_{A}}\right)\right]+1\right\}, \\
\xi_{A \rightarrow M}= & \frac{1-\xi_{s 0}}{2} \\
& \times \cos \left\{\frac{\pi}{\sigma_{s}^{\mathrm{cr}}-\sigma_{f}^{\mathrm{cr}}}\left[\sigma^{r}-\sigma_{f}^{\mathrm{cr}}-C_{M}\left(T-M_{s}\right)\right]\right\} \\
& +\frac{1+\xi_{s 0}}{2},
\end{aligned}
$$

where $M_{s}$ and $M_{f}$ denote the start and finish temperature points during the phase transformation from austenite to martensite and $A_{s}$ and $A_{f}$ denote the start and finish temperature points during the phase transformation from martensite to austenite, respectively. $C_{A}$ and $C_{M}$ are material constant of SMA wires which determine the influence of the stress on the transformation temperature. $\sigma_{s}^{\mathrm{cr}}$ and $\sigma_{f}^{\mathrm{cr}}$ denote the start and finish stress points of phase transformation, respectively, and the subscript " $\mathrm{s} 0$ " denotes martensite fraction induced by stress corresponding to initial state.
In (21a) and (21b), $\sigma_{1}$ and $\sigma_{2}$ denote the start and finish stress for the transformation $(M \rightarrow A) ; \sigma_{3}$ denotes the start stress for the transformation $(A \rightarrow M)$.

The phase transformation coefficient $\Omega(\xi)$ and the elastic modulus $E_{s}(\xi)$ can be expressed, respectively, as

$$
\begin{gathered}
E(\xi)=E_{A}+\xi\left(E_{M}-E_{A}\right), \\
\Omega(\xi)=-\varepsilon_{L} E(\xi),
\end{gathered}
$$

where $E_{M}$ and $E_{A}$ denote Young's modulus in the martensite and austenite phase, respectively, and $\varepsilon_{L}$ is recovery strain limit.

\section{Solution Method of Motion Equations}

In order to find the approximate solution of the rotating composite shaft, the quantities $U_{2}(x, t), U_{3}(x, t), \theta_{y}(x, t)$, and $\theta_{z}(x, t)$ are assumed in the form

$$
\begin{aligned}
& U_{2}(x, t)=\sum_{j=1}^{N} U_{2 j}(t) \alpha_{j}(x), \\
& U_{3}(x, t)=\sum_{j=1}^{N} U_{3 j}(t) \alpha_{j}(x), \\
& \theta_{y}(x, t)=\sum_{j=1}^{N} \Theta_{y j}(t) \psi_{j}(x), \\
& \theta_{z}(x, t)=\sum_{j=1}^{N} \Theta_{z j}(t) \psi_{j}(x),
\end{aligned}
$$

where

$$
\begin{aligned}
& \alpha_{j}=\sin \frac{j \pi}{L} x, \\
& \psi_{j}=\cos \frac{j \pi x}{L} .
\end{aligned}
$$

Substituting (24) into the governing (7) and applying Galerkin procedure, the following governing equations in matrix form can be found:

$$
[M]\{\ddot{X}\}+[C]\{\dot{X}\}+\left[K_{\Omega}+K_{1}\right]\{X\}=\{0\},
$$

where 
TABLE 1: Mechanical properties of composite material [5].

\begin{tabular}{lcccccc}
\hline$\rho\left(\mathrm{kg} / \mathrm{m}^{3}\right)$ & $E_{11}(\mathrm{GPa})$ & $E_{22}(\mathrm{GPa})$ & $G_{12}(\mathrm{GPa})$ & $G_{23}(\mathrm{GPa})$ & $\nu_{21}$ & $\nu_{32}$ \\
\hline 11528.15 & 206.8 & 5.17 & 3.1 & 2.55 & 0.00625 & 0.25 \\
\hline
\end{tabular}

$$
\begin{aligned}
& \mathbf{M}=\left[\begin{array}{cccc}
b_{1} E_{i j} & 0 & 0 & 0 \\
0 & b_{1} E_{i j} & 0 & 0 \\
0 & 0 & -b_{4} F_{i j} & 0 \\
0 & 0 & 0 & -b_{5} F_{i j}
\end{array}\right], \quad \mathbf{C}=\left[\begin{array}{cccc}
0 & -2 b_{1} \Omega E_{i j} & 0 & 0 \\
2 b_{1} \Omega E_{i j} & 0 & 0 & 0 \\
0 & 0 & 0 & 0 \\
0 & 0 & 0 & 0
\end{array}\right], \quad \mathbf{K}_{\Omega}=\left[\begin{array}{cccc}
-b_{1} \Omega^{2} E_{i j} & 0 & 0 & 0 \\
0 & -b_{1} \Omega^{2} E_{i j} & 0 & 0 \\
0 & 0 & 0 \\
0 & 0 & 0 \\
0 & 0 & 0
\end{array}\right], \\
& \mathbf{K}_{1}=\left[\begin{array}{cccc}
\left(-k_{55}+N^{\mathrm{SMA}}-N^{\Delta T}\right) I_{i j} & 0 & k_{55} J_{i j} & -k_{35} K_{i j} \\
0 & \left(-k_{66}+N^{\mathrm{SMA}}-N^{\Delta T}\right) I_{i j} & -k_{46} K_{i j} & k_{66} J_{i j} \\
-k_{55} O_{i j} & -k_{46} P_{i j} & -k_{44} Q_{i j}+k_{55} F_{i j} & 0 \\
-k_{35} P_{i j} & -k_{66} O_{i j} & 0 & -k_{33} Q_{i j}+k_{66} F_{i j}
\end{array}\right] \text {, } \\
& (i, j=1,2, \ldots, N) \text {, } \\
& (i, j=1,2, \ldots, N) \text {, }
\end{aligned}
$$

$$
\begin{array}{cc}
E_{i j}=\int_{0}^{L} \alpha_{i} \alpha_{j} d x, & F_{i j}=\int_{0}^{L} \psi_{i} \psi_{j} d x, \\
I_{i j}=\int_{0}^{L} \alpha_{i} \alpha_{j}^{\prime \prime}, & J_{i j}=\int_{0}^{L} \alpha_{i} \psi_{j}^{\prime} d x, \\
K_{i j}=\int_{0}^{L} \alpha_{i} \psi_{j}^{\prime \prime} d x, & O_{i j}=\int_{0}^{L} \psi_{i} \alpha_{j}^{\prime} d x, \\
P_{i j}=\int_{0}^{L} \psi_{i} \alpha_{j}^{\prime \prime} d x, & Q_{i j}=\int_{0}^{L} \psi_{i} \psi_{j}^{\prime \prime} d x, \\
& (i, j=1,2, \ldots, N) .
\end{array}
$$

Herein, the generalized displacements can be defined as

$$
\begin{array}{r}
\mathbf{X}^{T}=\left\{U_{2 j}(t), U_{3 j}(t), \Theta_{y j}(t), \Theta_{z j}(t)\right\}_{1 \times 4 N} \\
(j=1,2 \ldots, N) .
\end{array}
$$

From the matrix Equation (26), the eigenvalue problem of the rotating composite shaft can be expressed as

$$
\mathbf{A Y}=\lambda \mathbf{Y}
$$

where

$$
\mathbf{Y}=\left(\begin{array}{ll}
\mathbf{X} \dot{\mathbf{X}}
\end{array}\right)^{\mathbf{T}}, \quad A=\left(\begin{array}{cc}
\mathbf{0} & \mathbf{I} \\
-\mathbf{M}^{-1}\left(\mathbf{K}_{\Omega}+\mathbf{K}_{1}\right) & -\mathbf{M}^{-1} \mathbf{C}
\end{array}\right)
$$

Lower frequencies are primarily concerned in order to investigate the dynamic behavior of rotating composite shaft system. If there is a value of $N$ for which any increase in $N$ will not significantly change the eigenvalues associated with these lower frequencies, then the eigenvalues are considered to be converged at this value of $N$.
In (26) the stiffness matrix is made up of three components: the elastic stiffness of the shaft with stiffness coefficients $k_{i j}$ (see $\mathbf{K}_{1}$ in (27)), the geometric stiffness that accounts for the axial tension due to thermal expansion and SMA wires activation, and the stiffness $\mathbf{K}_{\Omega}$ due to the shaft rotation. It should be remarked that the stiffness matrix of the shaft is reduced by the rotational stiffness matrix $\mathbf{K}_{\Omega}$. However, on the other hand, if the total axial tension of the shaft, which is the sum of $N^{\text {SMA }}$ and $N^{\Delta T}$, is high enough such that $\left(N^{\mathrm{SMA}}-N^{\Delta T}\right)$ is positive then the stiffness of the shaft can been enhanced. Thus, it can be seen that the SMA wires activation plays an important role in controlling stiffness of the shaft and maintaining its stability at higher rotating speed. 


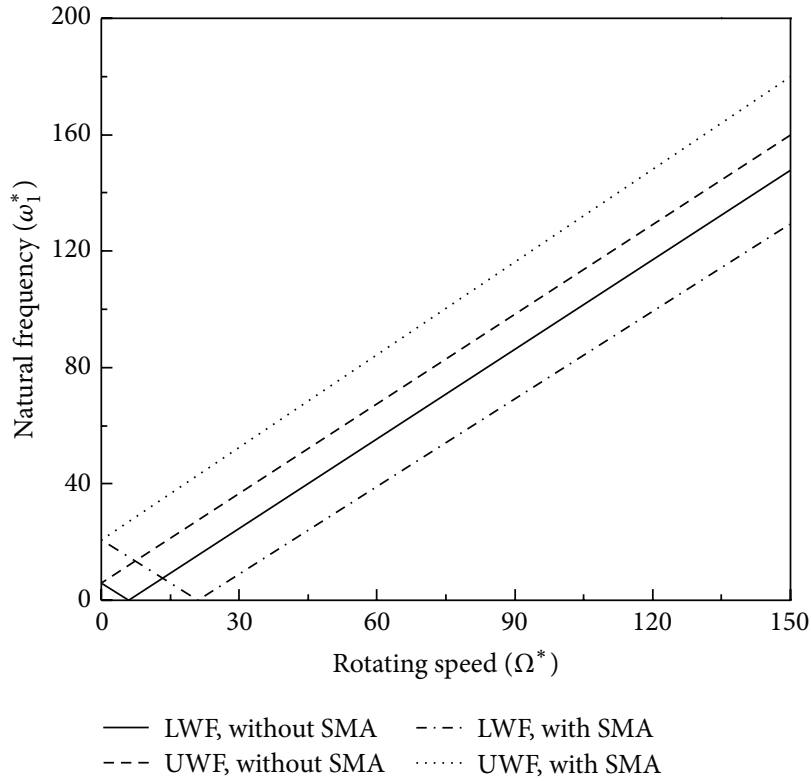

(a)

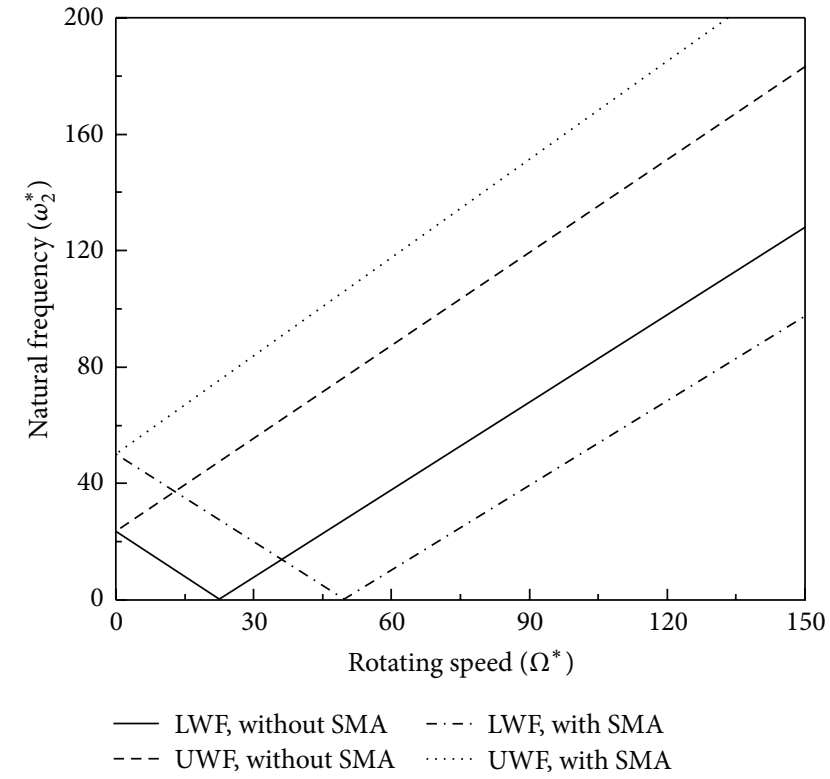

(b)

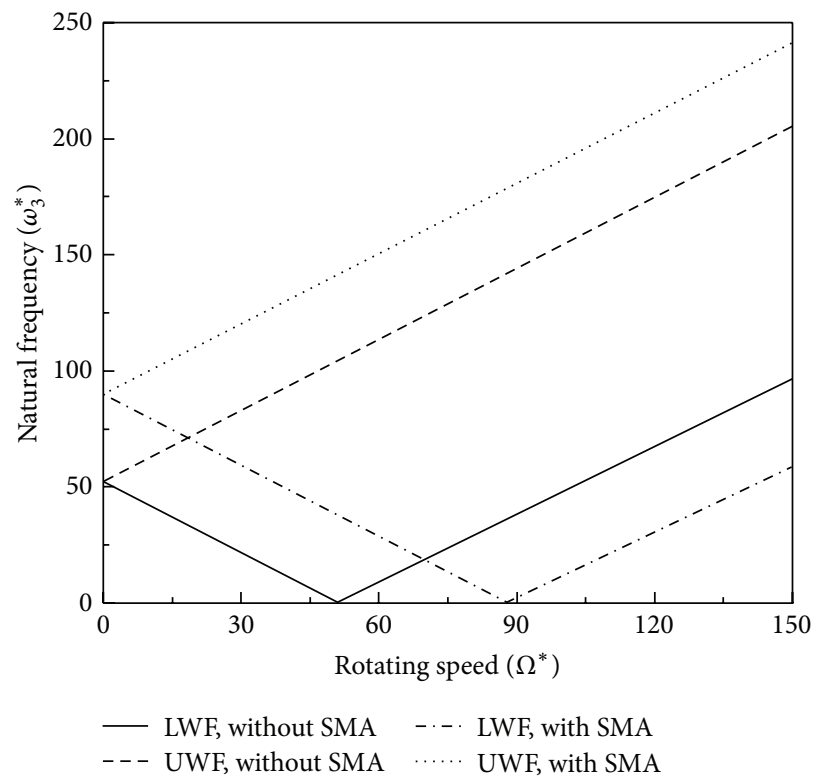

(c)

FIGURE 2: The first three natural frequencies versus rotating speeds of the shaft without SMA and with SMA $\left(\theta=30^{\circ} ; T=50^{\circ} \mathrm{C} ; V_{s}=0.24\right.$; $\left.\varepsilon_{0}=0.067\right)$.

TABLE 3: Comparison of the natural frequencies of a cantilever composite shaft without shear deformation.

\begin{tabular}{|c|c|c|c|c|c|c|}
\hline$\Omega^{*}$ & $\omega_{1}{ }^{*}$ & $\omega_{2}{ }^{*}$ & $\omega_{3}{ }^{*}$ & $\omega_{4}{ }^{*}$ & $\omega_{5}{ }^{*}$ & $\omega_{6}{ }^{*}$ \\
\hline 0 & 3.5160 & 3.5160 & 22.0345 & 22.0345 & 61.6973 & 61.6973 \\
\hline Reference [22] & 3.5160 & 3.5160 & 22.0340 & 22.0340 & 61.6970 & 61.6970 \\
\hline 2 & 1.5160 & 5.5160 & 20.0345 & 24.0345 & 59.6973 & 69.6973 \\
\hline Reference [22] & 1.5160 & 5.5160 & 20.0340 & 24.0340 & 59.6970 & 63.6970 \\
\hline 3.5 & 0.0160 & 7.0160 & 18.5345 & 25.5345 & 58.1973 & 65.1973 \\
\hline Reference [22] & 0.0000 & 7.0160 & 18.5340 & 25.5340 & 58.1970 & 65.1970 \\
\hline 4 & - & 7.5160 & 18.0345 & 26.0345 & 57.6973 & 65.6973 \\
\hline Reference [22] & - & 7.5160 & 18.0340 & 26.0340 & 57.6970 & 65.6970 \\
\hline 8 & - & 11.5160 & 14.0345 & 3.30345 & 53.6973 & 69.6973 \\
\hline Reference [22] & - & 11.5160 & 14.0340 & 30.0340 & 53.6970 & 69.6970 \\
\hline
\end{tabular}




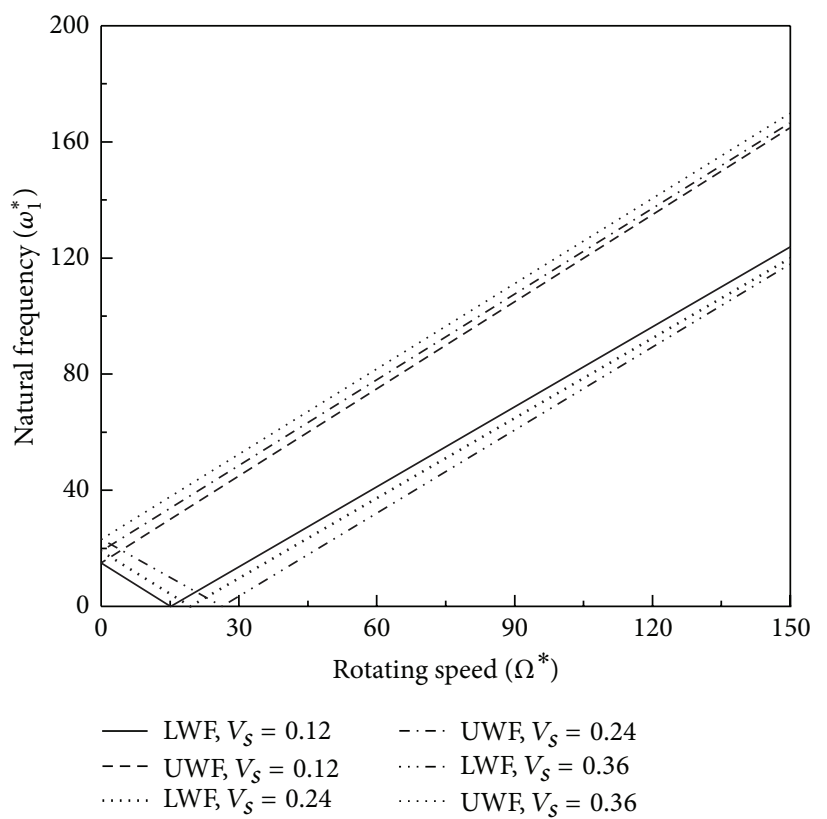

(a)

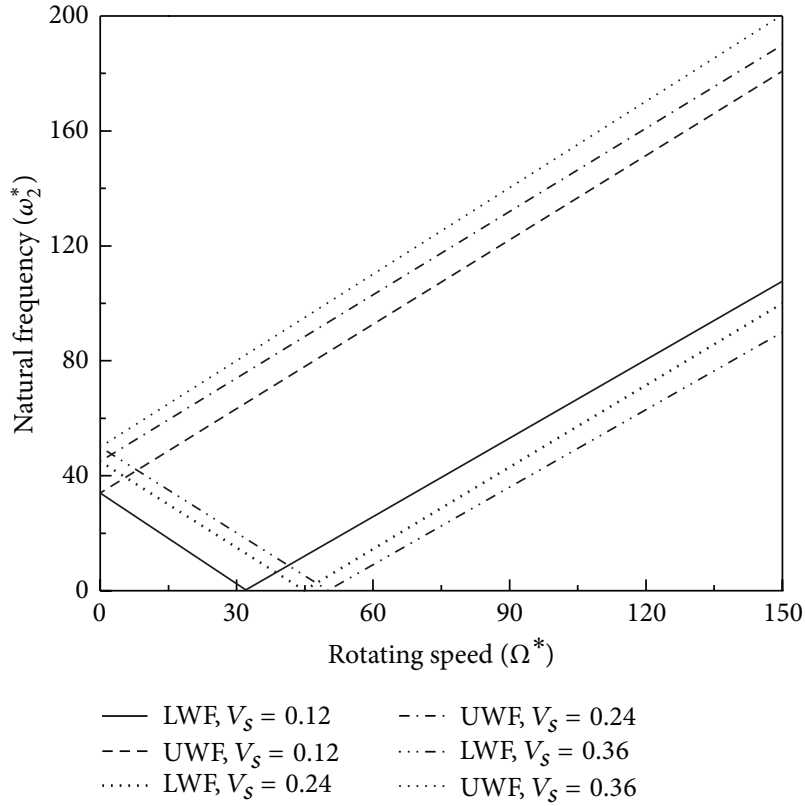

(b)

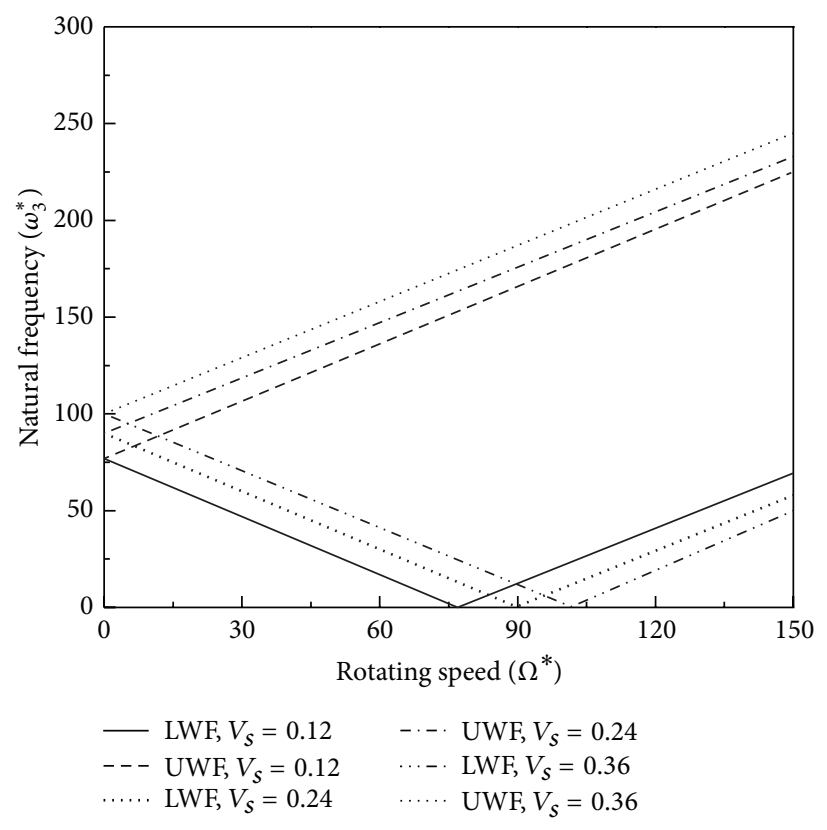

(c)

FIgURE 3: The first three natural frequencies versus rotating speed for different SMA wire fractions $\left(\theta=30^{\circ} ; \mathrm{T}=50^{\circ} \mathrm{C} ; \varepsilon_{0}=0.067\right)$.

\section{Numerical Results and Discussion}

The numerical calculations are performed by considering the shaft made of graphite-epoxy whose elastic characteristics are listed in Table 1. The shaft has geometrical characteristics as $r=0.127 \mathrm{~m}, L=2.023 \mathrm{~m}, h=0.381 \mathrm{~mm}$. The SMA wires used in the numerical simulations are listed in Table 2.

The numerical results will be given in terms of the normalized natural frequencies and rotating rate that are defined by $\omega^{*}=\omega / \omega_{0}, \Omega^{*}=\Omega / \omega_{0}$, where the normalizing factor $\omega_{0}=138.85 \mathrm{rad} / \mathrm{s}$ is the fundamental frequency of the nonrotating shaft with $\theta=0^{\circ}$ and corresponds to the case of the absence of the SMA activation $\left(N^{\mathrm{SMA}}=0\right)$ and of thermal effect $\left(N^{\Delta T}=0\right)$.

The natural frequencies of a cantilever composite shaft obtained for without shear deformation using the present model together with those obtained in [22] are shown in Table 3 for different rotating speeds. A perfect agreement of numerical results with those in [22] can be seen. 


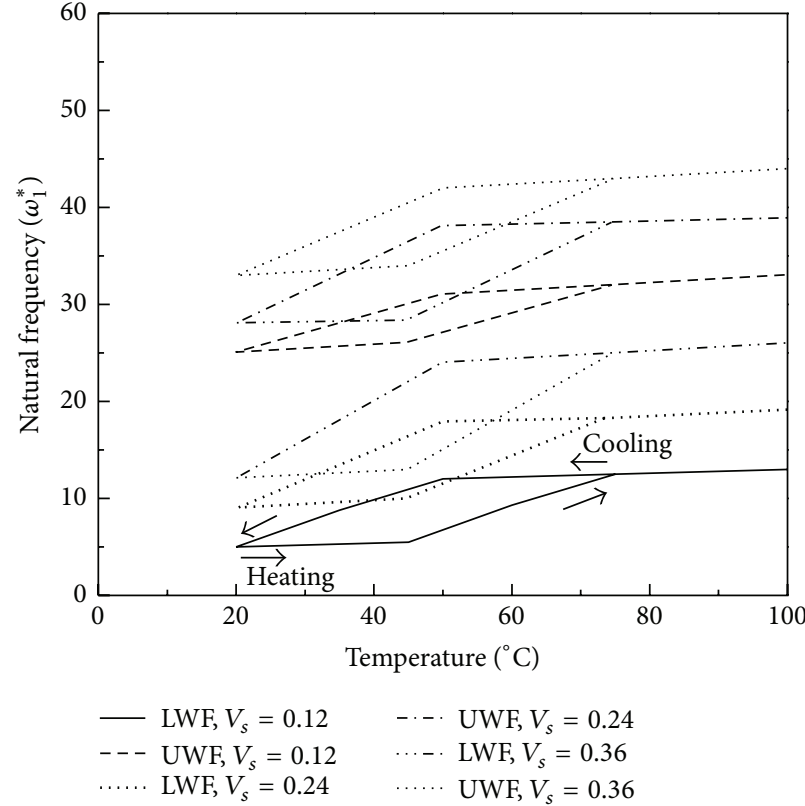

(a)

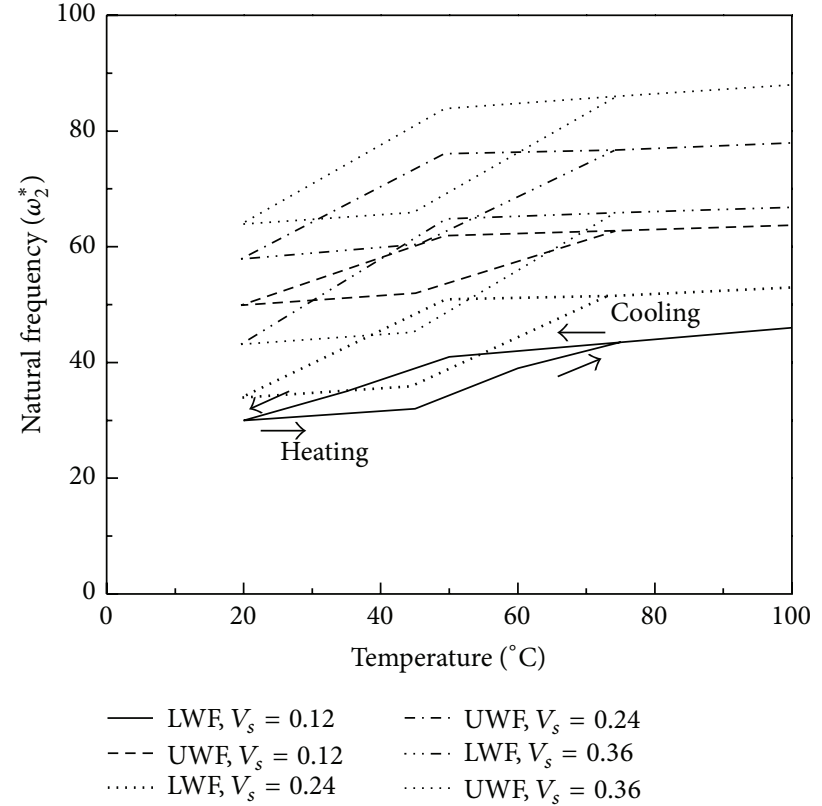

(b)

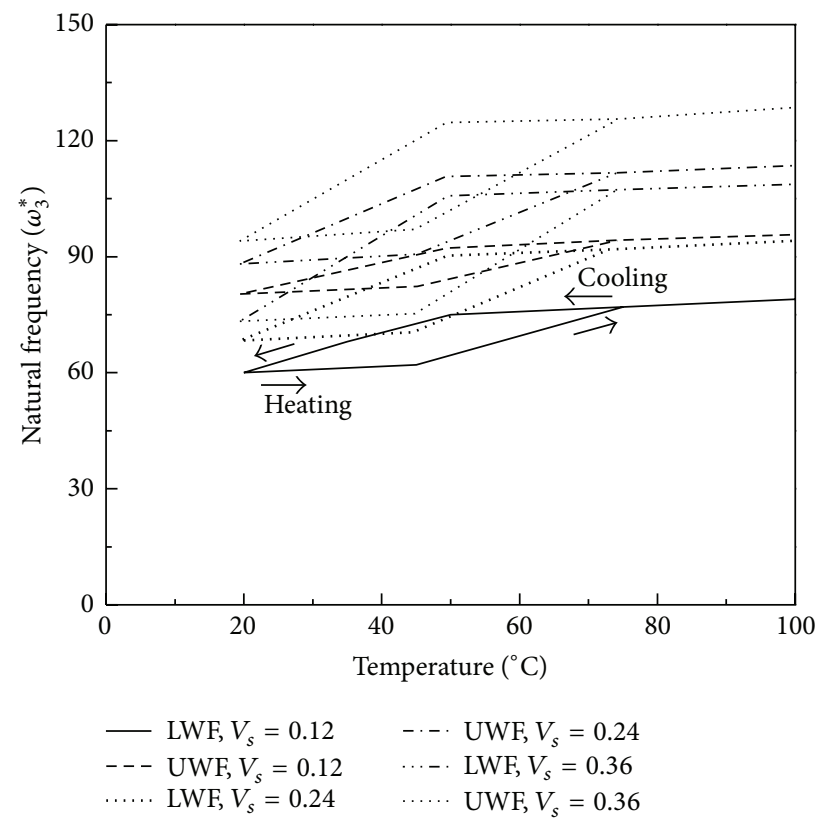

(c)

FiguRE 4: The first three natural frequencies versus temperature for different SMA wire fractions $\left(\Omega^{*}=5 \mathrm{rad} / \mathrm{s} ; \theta=30^{\circ} ; \varepsilon_{0}=0.067\right)$.

In order to examine the influence of the number of mode shape functions used in the solution of the equation on the accuracy of the results, the numerical results of natural frequency are shown in Table 4 for an increasing number of mode shape functions. From Table 4, it can be seen that to obtain an accurate result of the first three natural frequencies, no more than six mode shape functions are required. This indicates clearly that the convergence of the present model is quite good.
Based on mode convergence examination, it is found that $N=6$ gives suitably converged eigenvalues. So for all results given in this paper, $N=6$ unless otherwise noted.

Figure 2 shows the variations of the first three natural frequencies versus rotating speed for without SMA activation and with SMA activation $\left(\theta=30^{\circ}, T=50^{\circ} \mathrm{C}, V_{s}=0.24\right.$, $\left.\varepsilon_{0}=0.067\right)$. From this figure it clearly appears that when $\Omega^{*}=0$, a single zero-speed mode natural frequency is obtained. The reason is that for the circular cross-sectional 


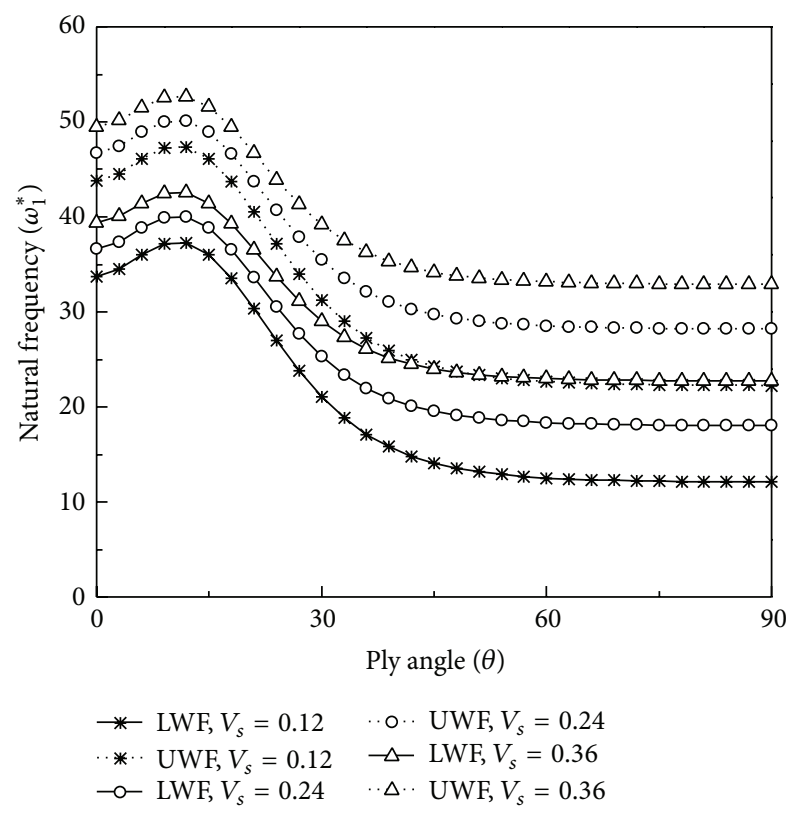

(a)

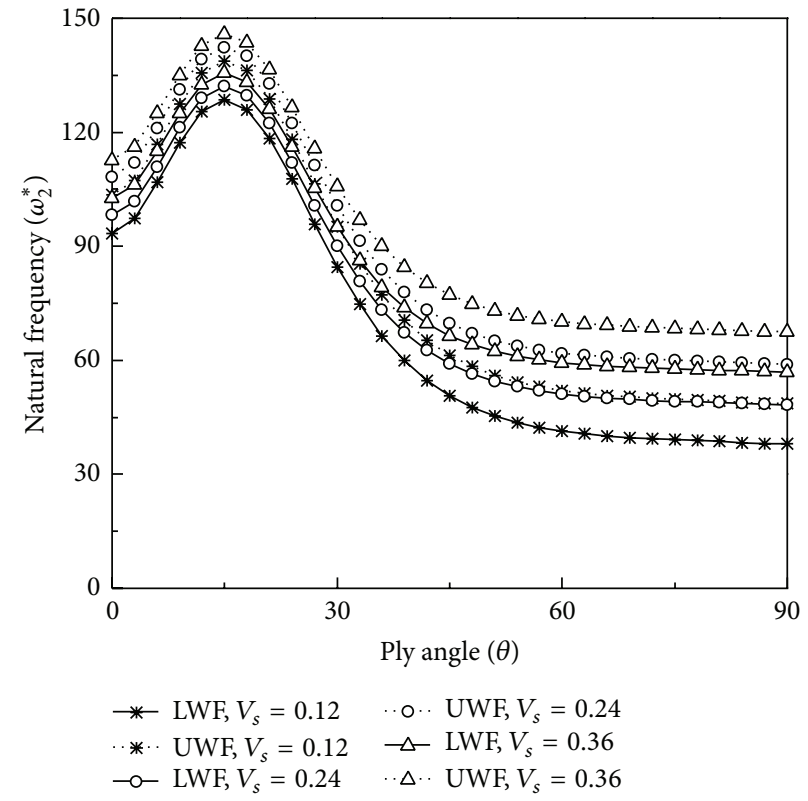

(b)

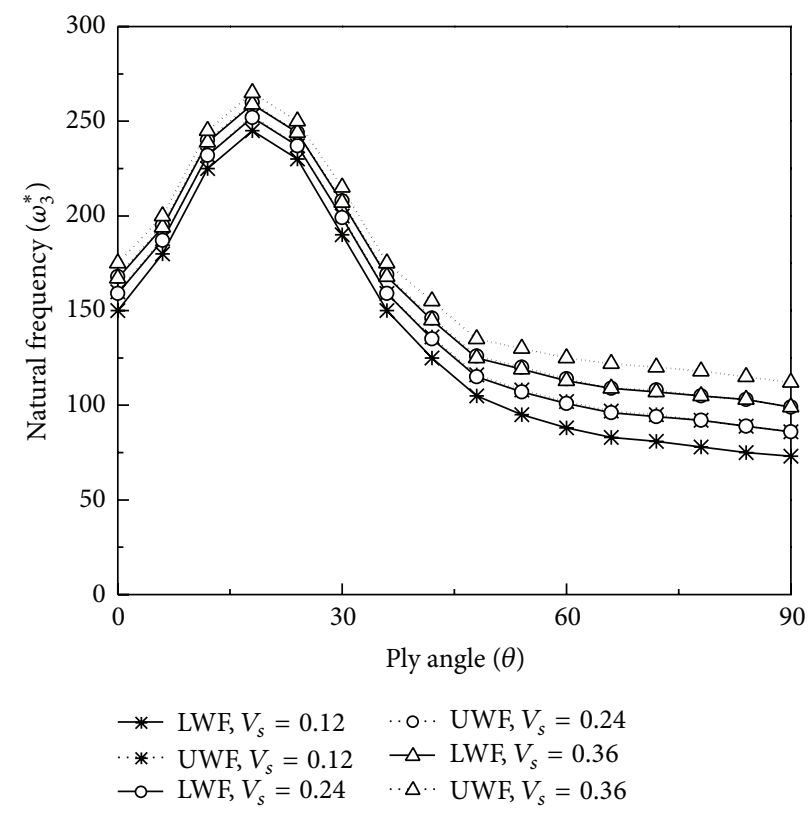

(c)

FIgURE 5: The first three natural frequencies versus ply-angle for different SMA wire fractions $\left(\Omega^{*}=5 \mathrm{rad} / \mathrm{s} ; \mathrm{T}=50^{\circ} \mathrm{C} ; \varepsilon_{0}=0.067\right)$.

TABLE 4: Effect of model number $N$ on natural frequencies $\left(\Omega^{*}=0\right.$ and $\theta=30^{\circ}$ ).

\begin{tabular}{lllcccc}
\hline$N$ & $\omega_{1}{ }^{*}$ & $\omega_{2}{ }^{*}$ & $\omega_{3}{ }^{*}$ & $\omega_{4}{ }^{*}$ & $\omega_{5}{ }^{*}$ & $\omega_{6}{ }^{*}$ \\
\hline 2 & 2.99 & 11.87 & - & - & - & - \\
4 & 2.98 & 11.68 & 25.17 & 42.41 & - & - \\
6 & 2.97 & 11.65 & 25.12 & 41.90 & 60.29 & 80.02 \\
8 & 2.97 & 11.64 & 25.10 & 41.84 & 60.21 & 79.22 \\
10 & 2.97 & 11.64 & 25.09 & 41.82 & 60.18 & 79.14 \\
\hline
\end{tabular}

shaft, the frequencies in transversal and lateral bending of each mode coincide. When $\Omega^{*} \neq 0$, the natural frequency "splits" into two distinct branches of bending vibration due to the gyroscopic effect, namely, the upper and lower frequency branches. The branch corresponding to the higher frequencies is associated with the up-whirling frequency (UWF) motion. Similarly, the branch corresponding to the lower frequencies is associated with the low-whirling frequency (LWF) motion. The minimum rotating rate at which the LWF becomes zero is referred to as the critical rotating speed that 


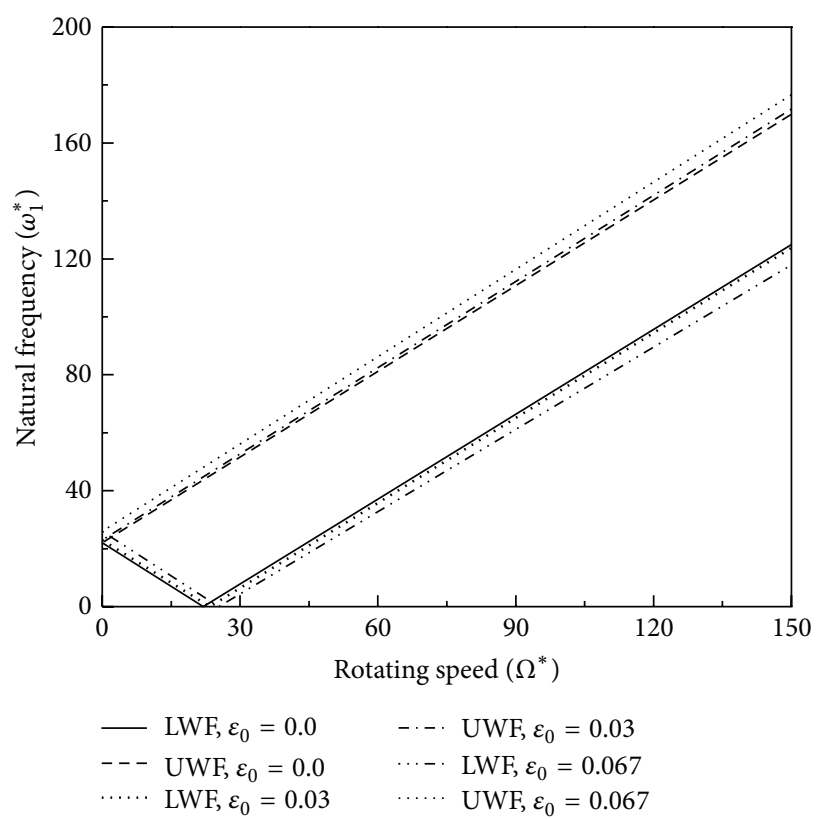

(a)

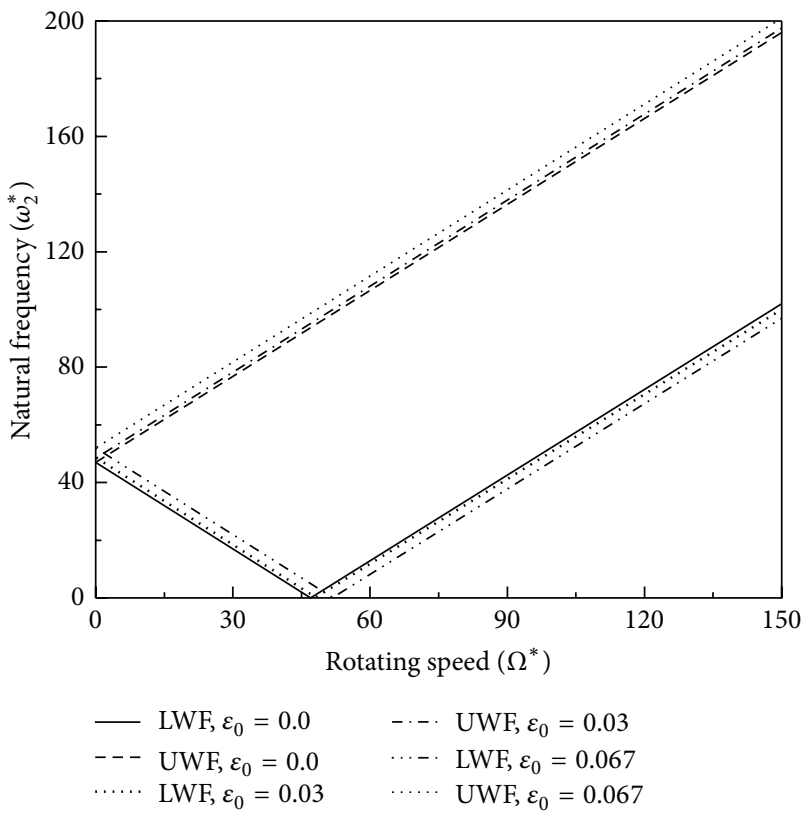

(b)

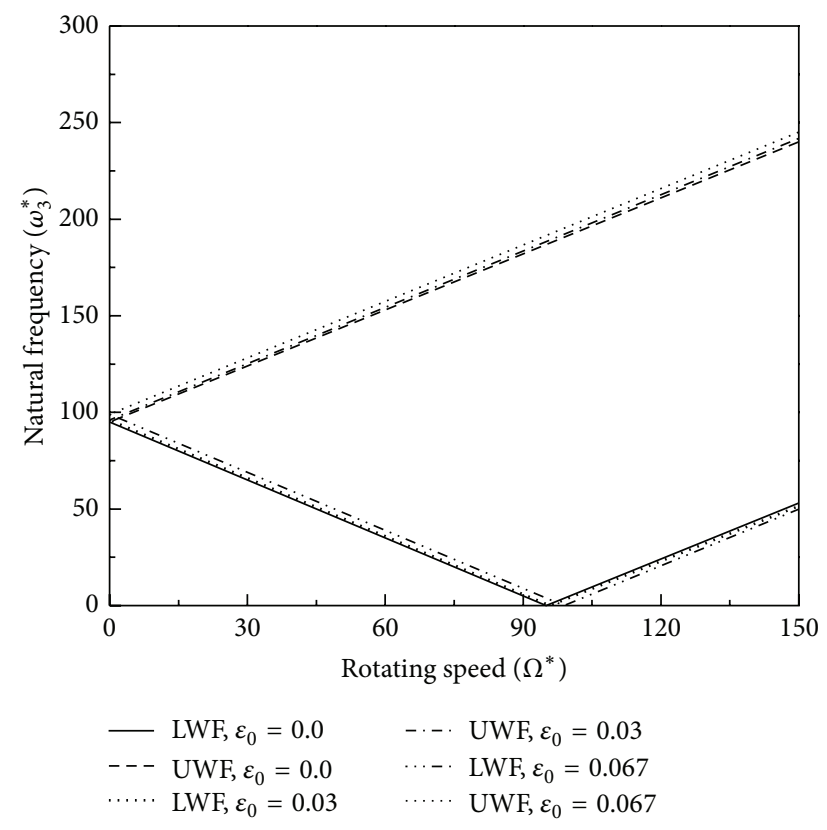

(c)

Figure 6: The first three natural frequencies versus rotating speed for the different initial strains of SMA wire $\left(\theta=30^{\circ} ; T=50^{\circ} \mathrm{C} ; V_{s}=0.36\right)$.

corresponds to the dynamical instability of the rotating shaft. In addition, this figure clearly indicates that SMA actuation can play a significant role in increasing the frequencies of the nonrotating shaft and postponing the occurrence of the whirling instability.

Figure 3 shows the variations of the first three natural frequencies versus rotating speed for different fractions of SMA wires at a temperature above $A_{f}\left(\theta=30^{\circ} ; T=50^{\circ} \mathrm{C}\right.$; $\left.\varepsilon_{0}=0.067\right)$. It is obviously seen that the natural frequencies of the nonrotating shaft and the critical rotating speed increase with increasing SMA wire fraction, because increasing of the fraction (or number) of the SMA wires results in generating a higher axial tension $N^{\mathrm{SMA}}$ inside the rotating shaft. It thus is apparent that the increase of the SMA wires which induces the increase of bending stiffness brings the increase of overall natural frequencies of the shaft.

Figure 4 shows that the variation of the first three natural frequencies as function of the temperature for different SMA wire fractions $\left(\Omega^{*}=5 \mathrm{rad} / \mathrm{s} ; \theta=30^{\circ} ; \varepsilon_{0}=0.067\right)$. Figure 4 is plotted for both UWF and LWF. 


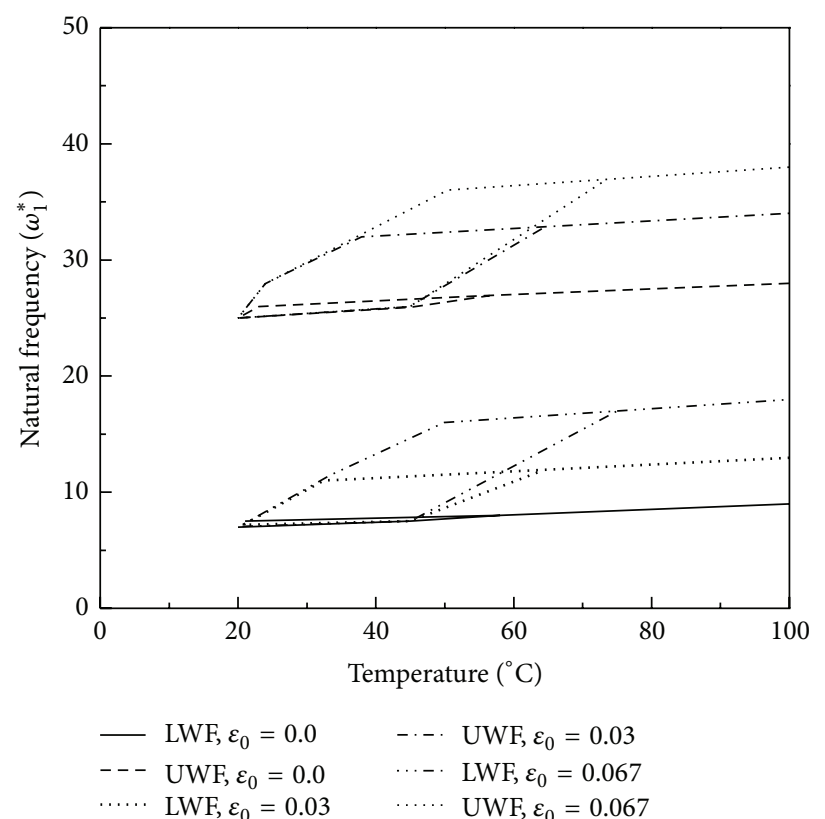

(a)

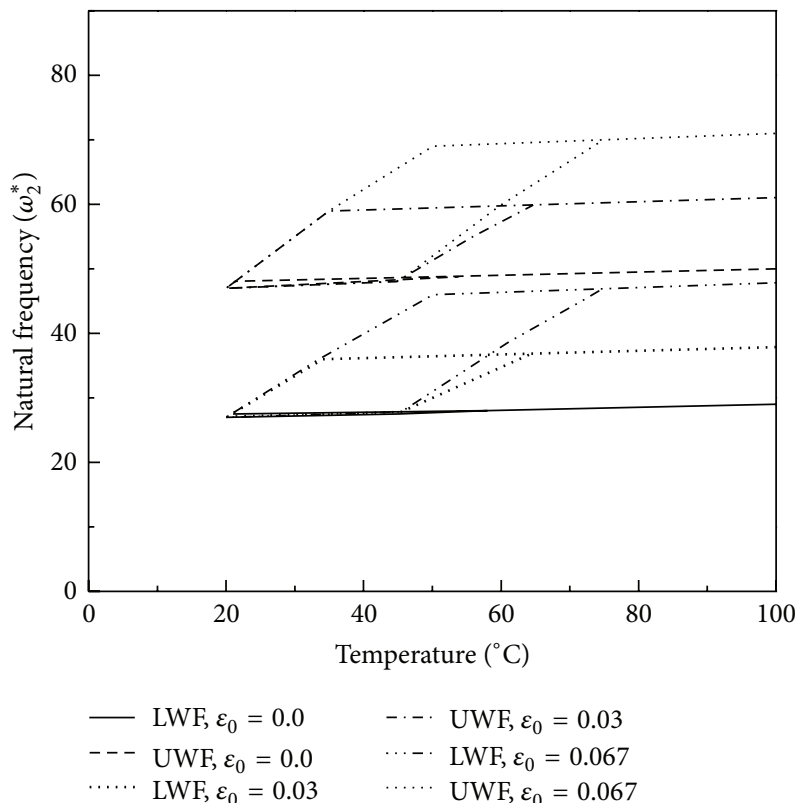

(b)

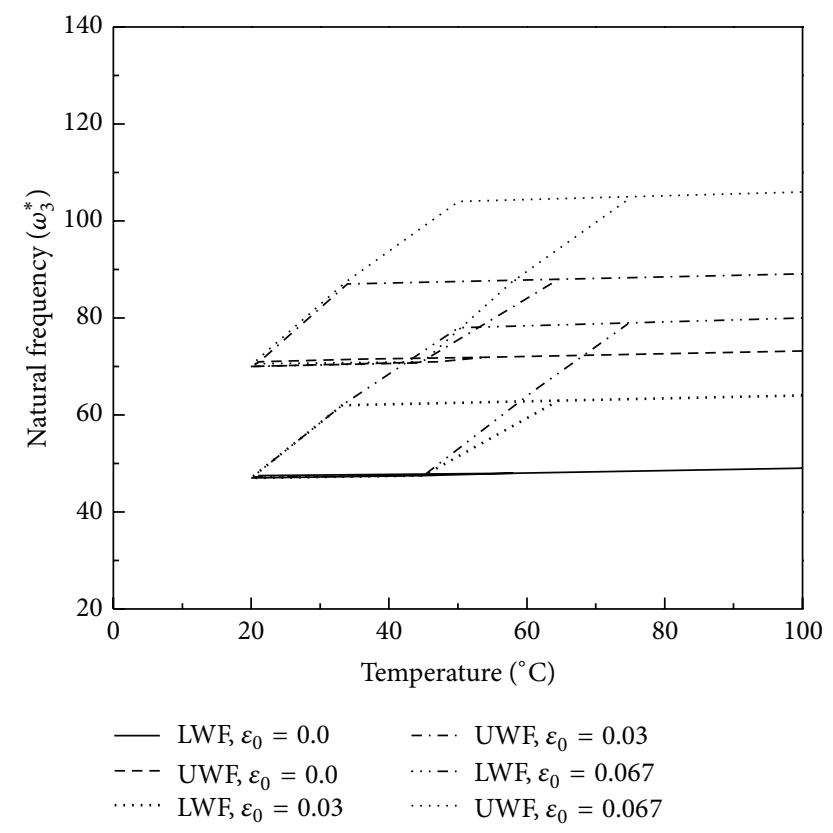

(c)

FIGURE 7: The first three natural frequencies versus temperature for the different initial strains of SMA wire $\left(\theta=30^{\circ} ; \mathrm{T}=50^{\circ} \mathrm{C} ; V_{s}=0.36\right)$.

The temperature is increased from $0^{\circ} \mathrm{C}$ to $100^{\circ} \mathrm{C}$ and then decreased from $100^{\circ} \mathrm{C}$ to $0^{\circ} \mathrm{C}$. The phase transformation from the martensite to the austenite $(M \rightarrow A)$ is induced in the SMA wires during heating, and the phase transformation from the austenite to the martensite $(A \rightarrow M)$ is induced during cooling. From Figure 4, the following phenomena can be observed: (1) the curves of natural frequencies and temperature are typical hysteresis loops in a thermal cycle, and the development of the natural frequencies can be divided into two stage, that is, the increase stage and the decline stage; (2) the natural frequencies increase with the increase in temperature during the phase transformation from the martensite to the austenite but decline with the decrease in temperature during the phase transformation from the austenite to the martensite; (3) the increase of the SMA wire fraction is accompanied by the shift of these hysteresis loops towards higher natural frequencies.

Figure 5 shows the variation of the first three natural frequencies with the ply-angle for different SMA wire fractions $\left(\Omega^{*}=5 \mathrm{rad} / \mathrm{s} ; T=50^{\circ} \mathrm{C} ; \varepsilon_{0}=0.067\right)$. The results 


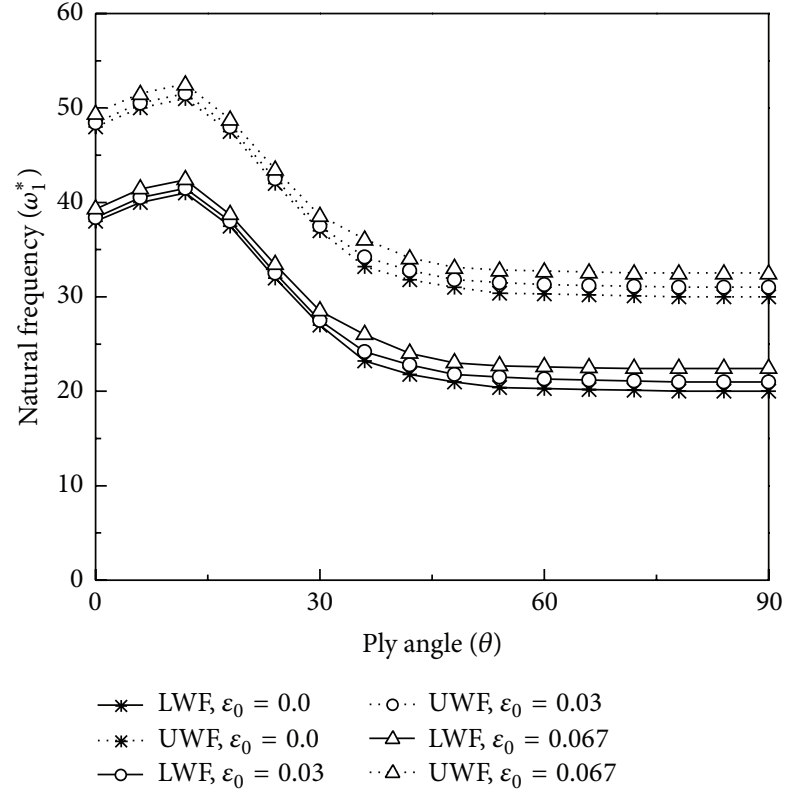

(a)

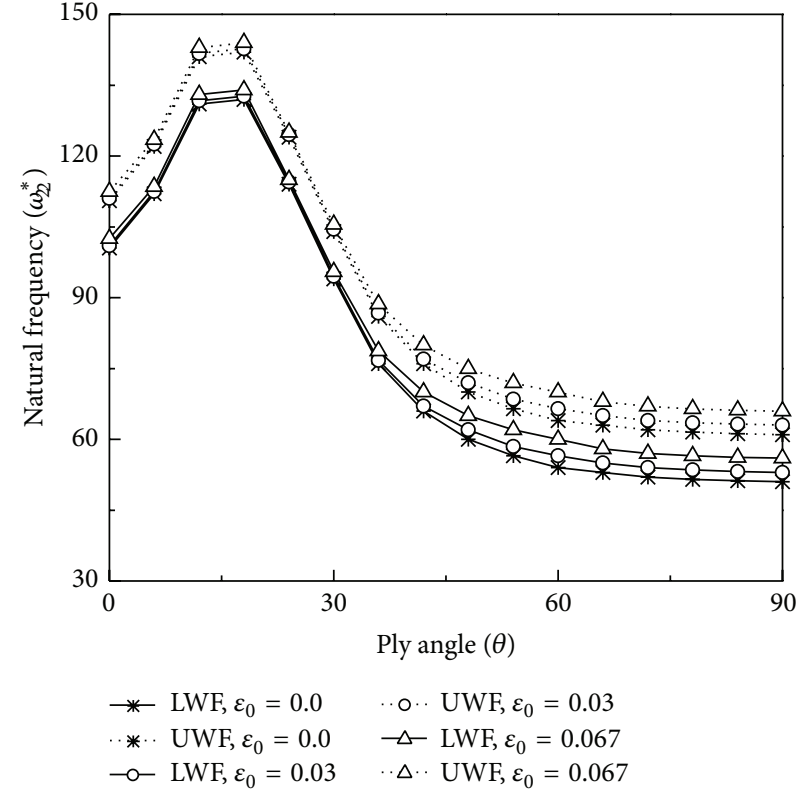

(b)

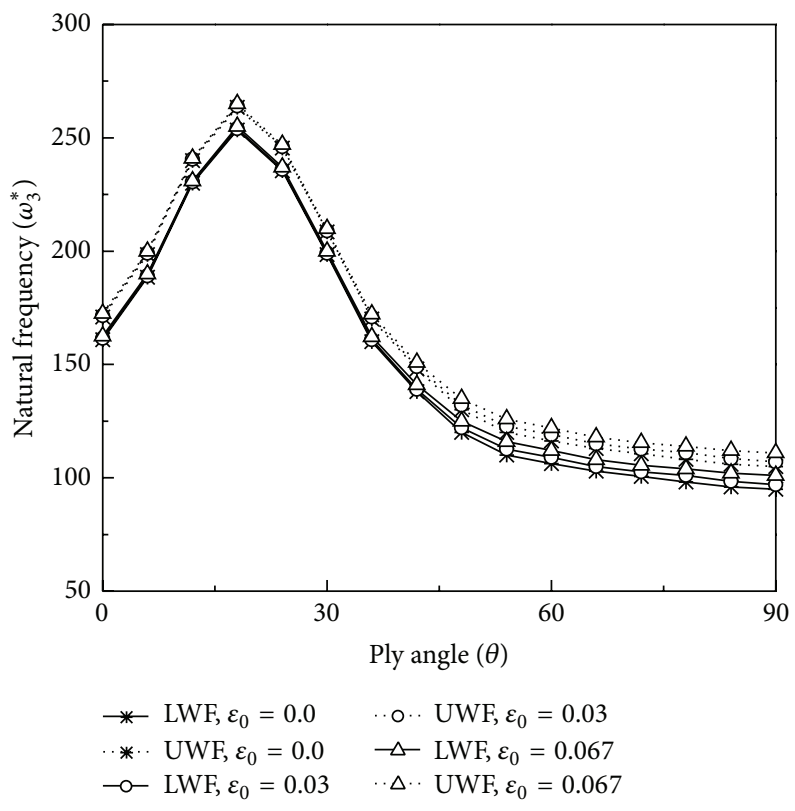

(c)

FIGURE 8: The first three natural frequencies versus ply-angle for the different initial strains of SMA wire $\left(\theta=30^{\circ} ; T=50^{\circ} \mathrm{C} ; V_{s}=0.36\right)$.

show that the effect of SMA wire fraction on the natural frequencies is substantial when the ply-angle is located near $90^{\circ}$. In addition, from Figure 5 it can be found that the trend of variation of natural frequencies with ply-angle is the same as that of the shaft without SMA actuation. Figure 5 also shows that as the SMA wire fraction increases, the natural frequencies increase.

Figure 6 shows the variations of the first three natural frequencies versus rotating speed for the different initial strains of SMA wire $\left(\theta=30^{\circ}, T=50^{\circ} \mathrm{C}, V_{s}=0.36\right)$. It can be seen that the natural frequencies of the rotating shaft increase with increasing of the initial strain of SMA wire.

Figure 7 shows the variation of the first three natural frequencies and temperature for the different initial strains of SMA wire $\left(\theta=30^{\circ} ; T=50^{\circ} \mathrm{C} ; V_{s}=0.36\right)$. The results show that there is an obvious change in the shapes of natural frequencies and temperature curves as the initial strain of SMA wire is increased.

Figure 8 shows the variation of the first three natural frequencies with the ply-angle for the different initial strains 


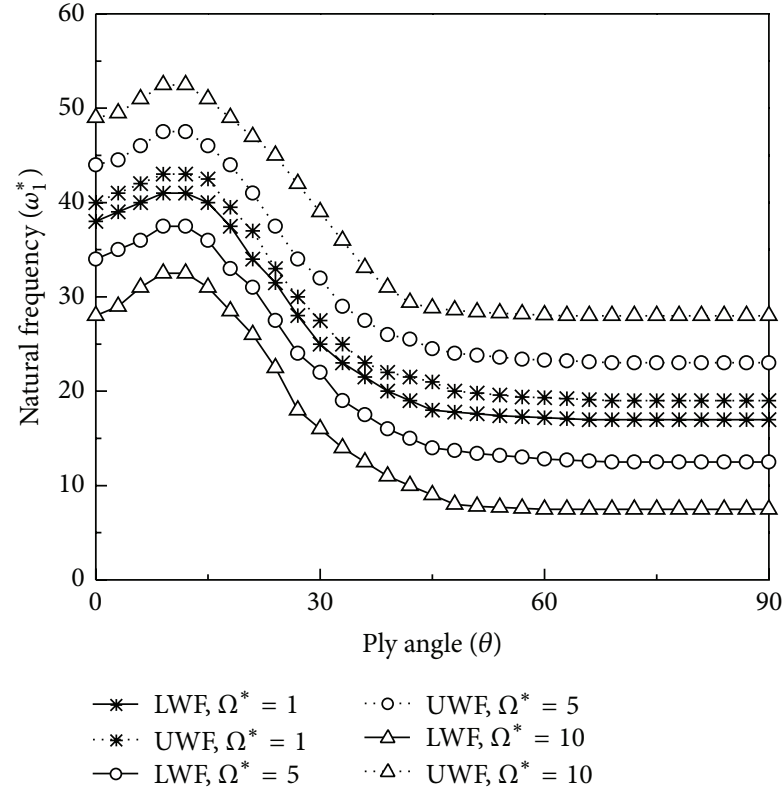

(a)

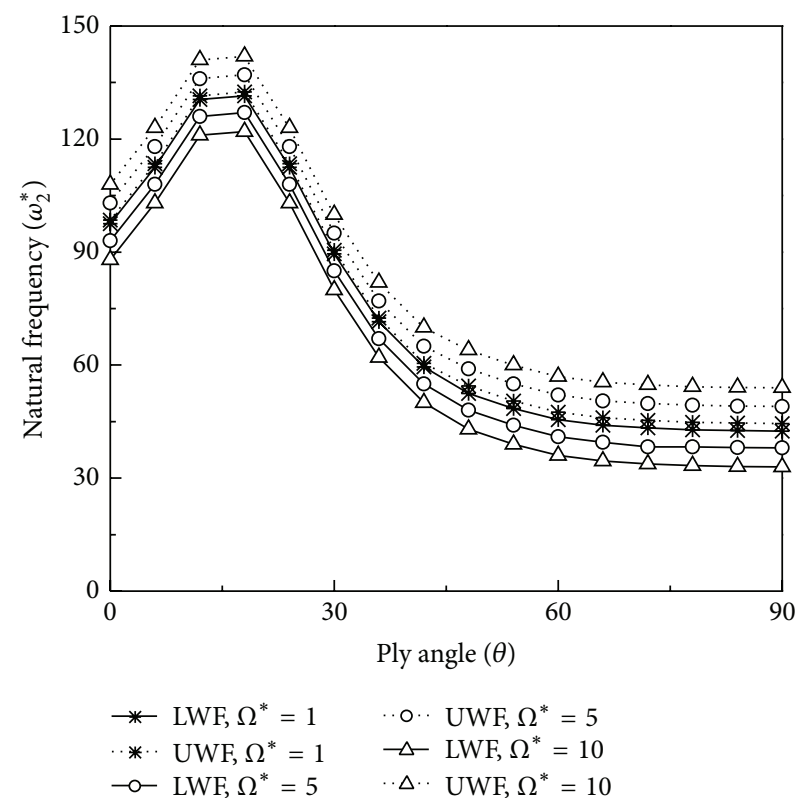

(b)

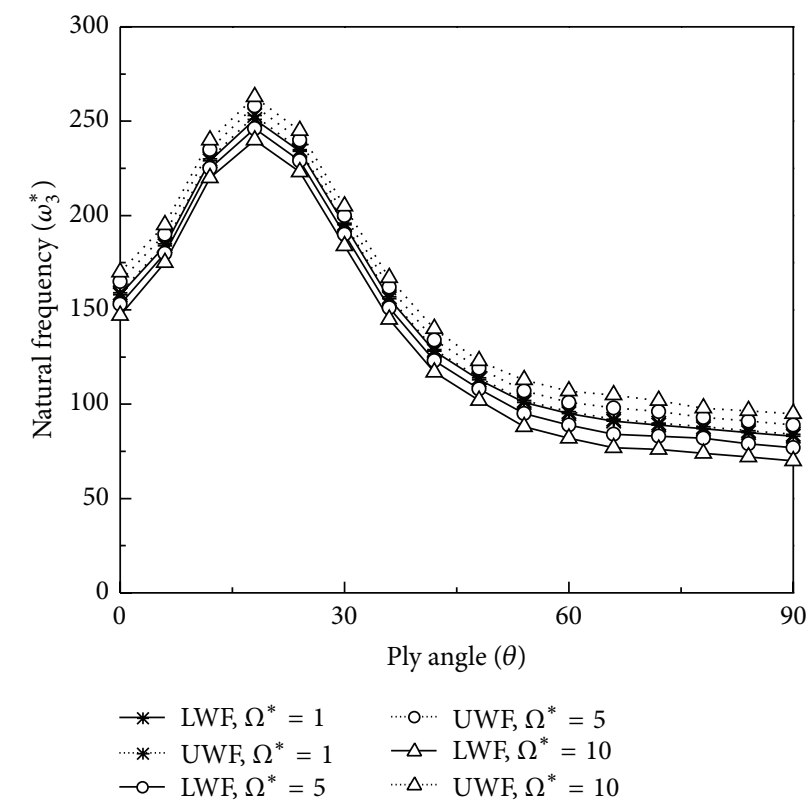

(c)

Figure 9: The first three natural frequencies versus ply-angle for different rotating speeds $\left(V_{s}=0.24 ; \theta=30^{\circ} ; T=50^{\circ} \mathrm{C} ; \varepsilon_{0}=0.067\right)$.

of SMA wire $\left(\Omega^{*}=5 \mathrm{rad} / \mathrm{s} ; T=50^{\circ} \mathrm{C} ; V_{s}=0.36\right)$. It can be noted that the effect of the initial strain of SMA wire on the natural frequencies is similar to that previously presented for the SMA wire fraction. However, the SMA wire fraction has a clear influence on the modes, while the initial strain of SMA wire appears to have a marginal effect on the modes.

Figure 9 shows the variation of the first three natural frequencies with the ply-angle for different rotating speeds $\left(V_{s}=0.24 ; \theta=30^{\circ} ; T=50^{\circ} \mathrm{C} ; \varepsilon_{0}=0.067\right)$. The results show that the increase of rotating speed is accompanied by both an upward shift of the UWF branches and by a downward shift of the LWF branches, which are similar to that in connection with the results of Figures 2, 3, and 6.

Figure 10 shows the variation of the first three natural frequencies versus ply-angle during heating and cooling at $50^{\circ} \mathrm{C}\left(V_{s}=0.12 ; \Omega^{*}=5 \mathrm{rad} / \mathrm{s} ; \varepsilon_{0}=0.067\right)$. For the same temperature, there are two natural frequencies which correspond to the heating and cooling processes, respectively (see Figure 4 ). Moreover, when rotating speed $\Omega^{*} \neq 0$ two different frequencies are produced. Thus, we can obtain totally four different curves at temperature $T=50^{\circ} \mathrm{C}$. 


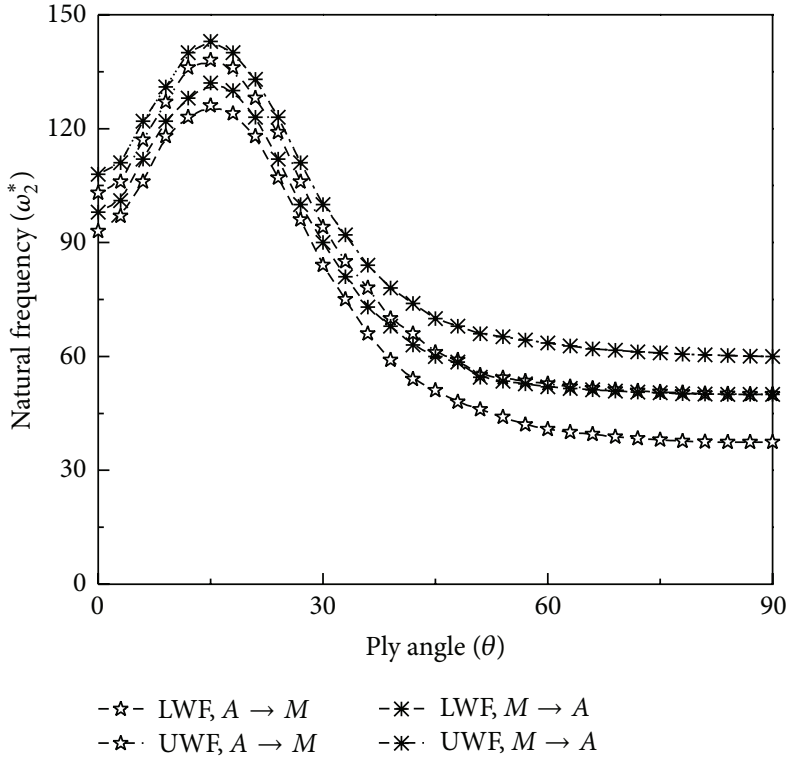

(a)

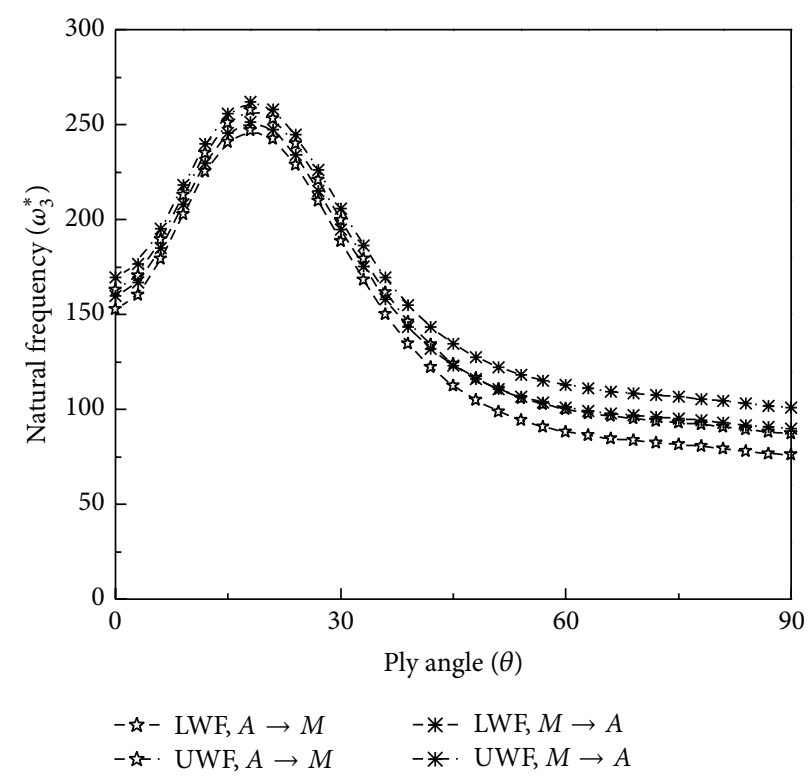

(b)

FIGURE 10: The first three natural frequencies versus ply angle during heating and cooling processes at $50^{\circ} \mathrm{C}\left(V_{s}=0.12 ; \Omega^{*}=5 \mathrm{rad} / \mathrm{s}\right.$; $\left.\varepsilon_{0}=0.067\right)$.

TABLE 5: The critical rotating speed corresponding to the different SMA wire fractions $\left(T=50^{\circ} \mathrm{C}, \varepsilon_{0}=0.067\right)$.

\begin{tabular}{lccccc}
\hline$V_{s}$ & 0.0 & 0.12 & 0.24 & 0.36 & 0.48 \\
\hline$\Omega_{\mathrm{cr}}^{*}$ & 2.64 & 14.28 & 19.66 & 23.62 & 26.81 \\
\hline
\end{tabular}

TABLE 6: The critical rotating speed corresponding to the different initial strains of SMA wire $\left(T=50^{\circ} \mathrm{C}, V_{s}=0.36\right)$.

\begin{tabular}{lccccc}
\hline$\varepsilon_{0}$ & 0.0 & 0.015 & 0.03 & 0.045 & 0.067 \\
\hline$\Omega_{\mathrm{cr}}^{*}$ & 21.80 & 22.50 & 22.96 & 23.29 & 23.62 \\
\hline
\end{tabular}

The effect of the fraction and the initial strain of SMA wires on the critical rotating speed during heating at $50^{\circ} \mathrm{C}$ is presented in Tables 5 and 6, respectively.

The significant effects of the SMA wire fraction on the critical rotating speed can be observed in Table 5 . However, as it appears from Table 6, the initial strain of SMA wires does not influence the critical rotating speed significantly.

\section{Conclusion}

A model was presented for the study of the vibration and stability of rotating thin-walled composite shaft embedded with SMA wires. The presented model was used to predict the natural frequencies and dynamical stability. Emphasis is placed on the study of the effects of SMA activation on the above dynamical behavior. From the present analysis and the numerical results, the following main conclusions can be obtained.

(1) The developed model provides means of predicting the natural frequency and critical rotating speed of rotating composite thin-walled shaft with SMA wires actuation.

(2) SMA wires activation can significantly postpone the occurrence of the whirling instability and increase the critical rotating speed through SMA phase transformation.

(3) The SMA wire fraction and ply-angle affect the actuation performance of SMA significantly. There is an obvious increase in the natural frequencies and the critical rotating speed as the SMA wire fraction is increased.

(4) The initial strain of SMA wire appears to have marginal effect on the critical rotating speed of the rotating shaft during heating.

\section{Conflict of Interests}

The authors declare that there is no conflict of interests regarding the publication of this paper.

\section{Acknowledgments}

The research is funded by the National Natural Science Foundation of China (Grant no. 11272190) and Shandong Provincial Natural Science Foundation of China (Grant no. ZR2011EEM031).

\section{References}

[1] S. P. Singh, H. B. H. Gubran, and K. Gupta, "Developments in dynamics of composite material shafts," International Journal of Rotating Machinery, vol. 3, no. 3, pp. 189-198, 1997. 
[2] B. S. Yang and W. D. Pilkey, "Accurate free vibration analysis for rotating shafts," in Proceedings of the ASME Rotating Machinery and Vehicle Dynamics, vol. 35, pp. 133-138, 1991.

[3] C.-D. Kim and C. W. Bert, "Critical speed analysis of laminated composite, hollow drive shafts," Composites Engineering, vol. 3, no. 7-8, pp. 633-643, 1993.

[4] C. W. Bert and C.-D. Kim, "Whirling of composite-material driveshafts including bending-twisting coupling and transverse shear deformation," Journal of Vibration and Acoustics, vol. 117, no. 1, pp. 17-21, 1995.

[5] O. Song, N.-H. Jeong, and L. Librescu, "Implication of conservative and gyroscopic forces on vibration and stability of an elastically tailored rotating shaft modeled as a composite thinwalled beam," Journal of the Acoustical Society of America, vol. 109, no. 3, pp. 972-981, 2001.

[6] L. W. Rehfield, "Design analysis methodology for composite rotor blades," in Proceedings of the 7th DoD/NASA Conference on Fibrous Composites in Structural Design, Denver, Colo, USA, June 1985.

[7] V. Berdichevsky, E. Armanios, and A. Badir, "Theory of anisotropic thin-walled closed-cross-section beams," Composites Engineering, vol. 2, no. 5-7, pp. 411-432, 1992.

[8] C. A. Rogers, C. Liang, and D. K. Barker, "Dynamic control concepts using shape memory alloy reinforced plates," in Proceedings of the Smart Materials Structures and Mathematical Issues, C. A. Rogers, Ed., pp. 39-62, Technomic Publishing, Lancaster, Pa, USA, 1989.

[9] A. Baz and T. Chen, "Performance of nitinol reinforced drive shafts," in Smart Structure and Intelligent Systems, vol. 1917 of Proceedings of the SPIE, pp. 791-708, 1993.

[10] K. Gupta, "Critical speed analysis of fibre reinforced composite rotor embedded with shape memory alloy wires," International Journal of Rotating Machinery, vol. 6, no. 3, pp. 201-213, 2000.

[11] S. Sawhney and S. K. Jain, Vibration control of fibre-reinforced composite rotor using shape memory alloy (SMA) wires [BTech Dissertation], IIT Delhi, New Delhi, India, 2001.

[12] A. Baz and T. Chen, "Torsional stiffness of NITINOL-reinforced composite drive shafts," Composites Engineering, vol. 3, no. 12, pp. 1119-1130, 1993.

[13] A. Tylikowski, "Dynamic stability of rotating composite shells with thermoactive shape memory alloy fibers," Journal of Thermal Stresses, vol. 21, no. 3-4, pp. 327-339, 1998.

[14] A. Tylikowski and R. B. Hetnarski, "Semiactive control of a shape memory alloy hybrid composite rotating shaft," International Journal of Solids and Structures, vol. 38, no. 50-51, pp. 9347-9357, 2001.

[15] K. Gupta, S. Sawhney, S. K. Jain, and A. K. Darpe, "Stiffness characteristics of fibre-reinforced composite shaft embedded with shape memory alloy wires," Defence Science Journal, vol. 53, no. 2, pp. 167-173, 2003.

[16] L. C. Brinson, "One-dimensional constitutive behavior of shape memory alloys: thermomechanical derivation with nonconstant material functions and redefined martensite internal variable," Journal of Intelligent Material Systems and Structures, vol. 4, no. 2, pp. 229-242, 1993.

[17] S.-Y. Oh, L. Librescu, and O. Song, "Vibration and instability of functionally graded circular cylindrical spinning thin-walled beams," Journal of Sound and Vibration, vol. 285, no. 4-5, pp. 1071-1091, 2005.

[18] L. Librescu, Elasto-Statics and Kinetics of Anisotropic and Heterogeneous Shell-Type Structures, Noordhoff International Publishers, Leyden, The Netherlands, 1975.
[19] E. C. Smith and I. Chopra, "Formulation and evaluation of an analytical model for composite box-beams," Journal of the American Helicopter Society, vol. 36, no. 3, pp. 23-35, 1991.

[20] K. Bhaskar and L. Librescu, "A geometrically non-linear theory for laminated anisotropic thin-walled beams," International Journal of Engineering Science, vol. 33, no. 9, pp. 1331-1344, 1995.

[21] S. S. Sun, G. Sun, F. Han, and J. S. Wu, "Thermoviscoelastic analysis for a polymeric composite plate with embedded shape memory alloy wires," Composite Structures, vol. 58, no. 2, pp. 295-302, 2002.

[22] J. R. Banerjee and H. Su, "Development of a dynamic stiffness matrix for free vibration analysis of spinning beams," Computers and Structures, vol. 82, no. 23-26, pp. 2189-2197, 2004. 

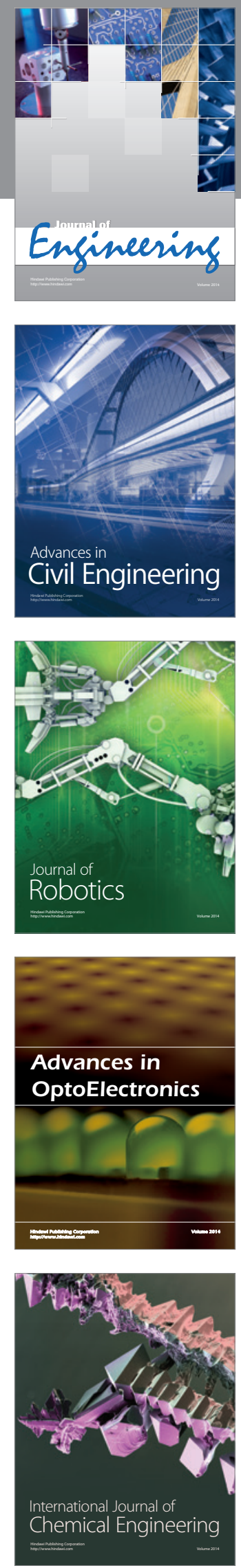

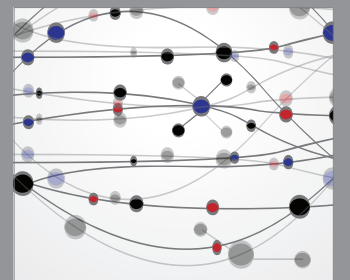

The Scientific World Journal
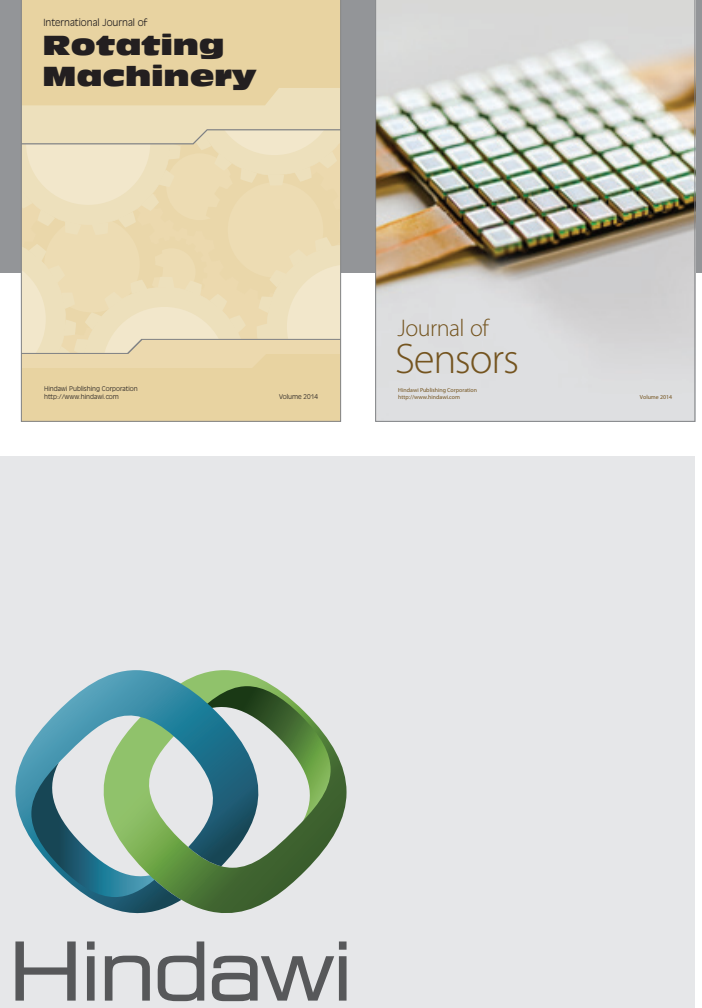

Submit your manuscripts at http://www.hindawi.com
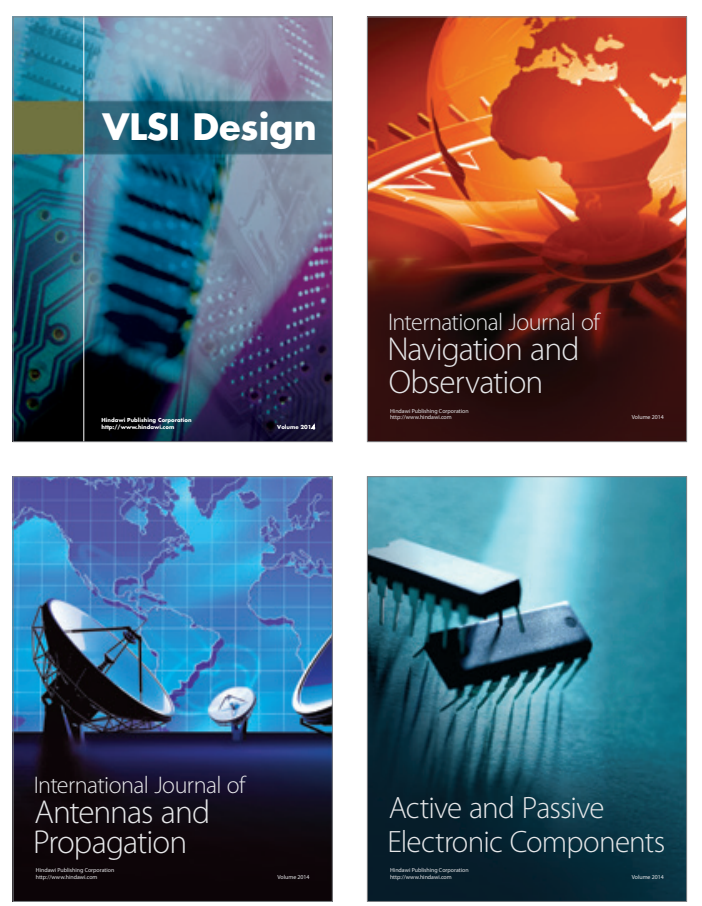
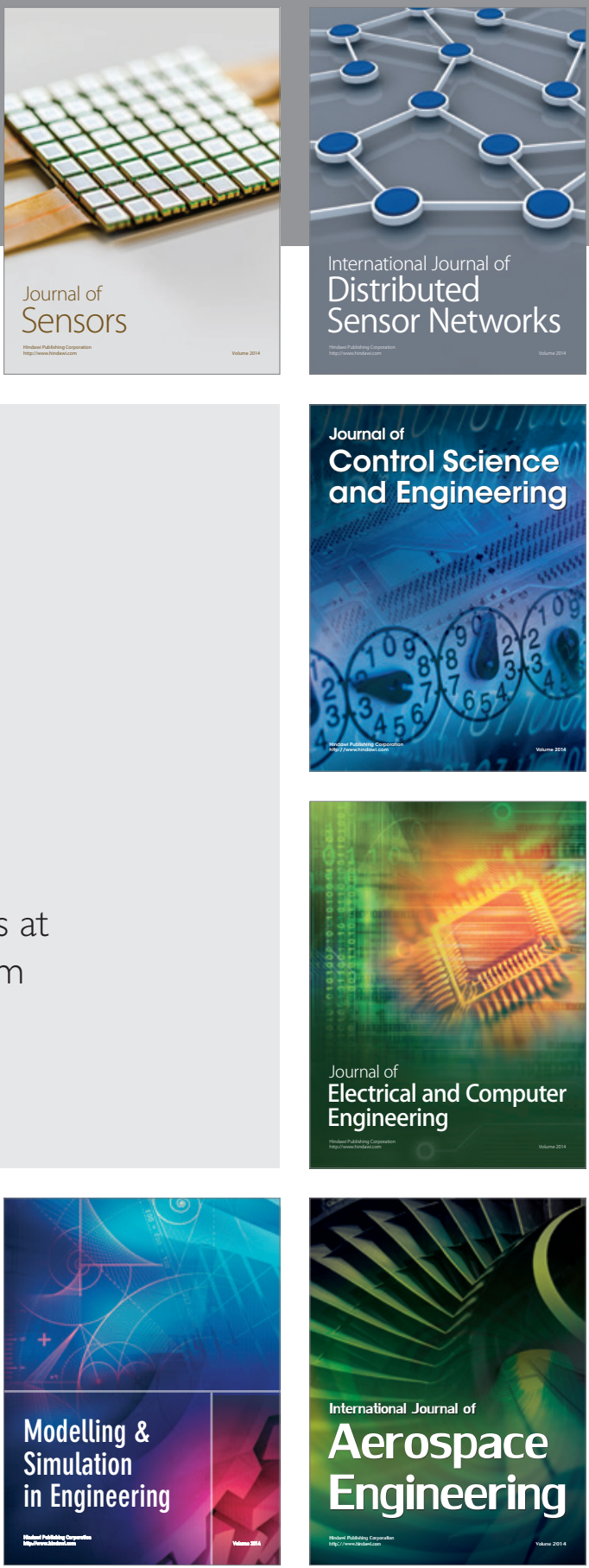

Journal of

Control Science

and Engineering
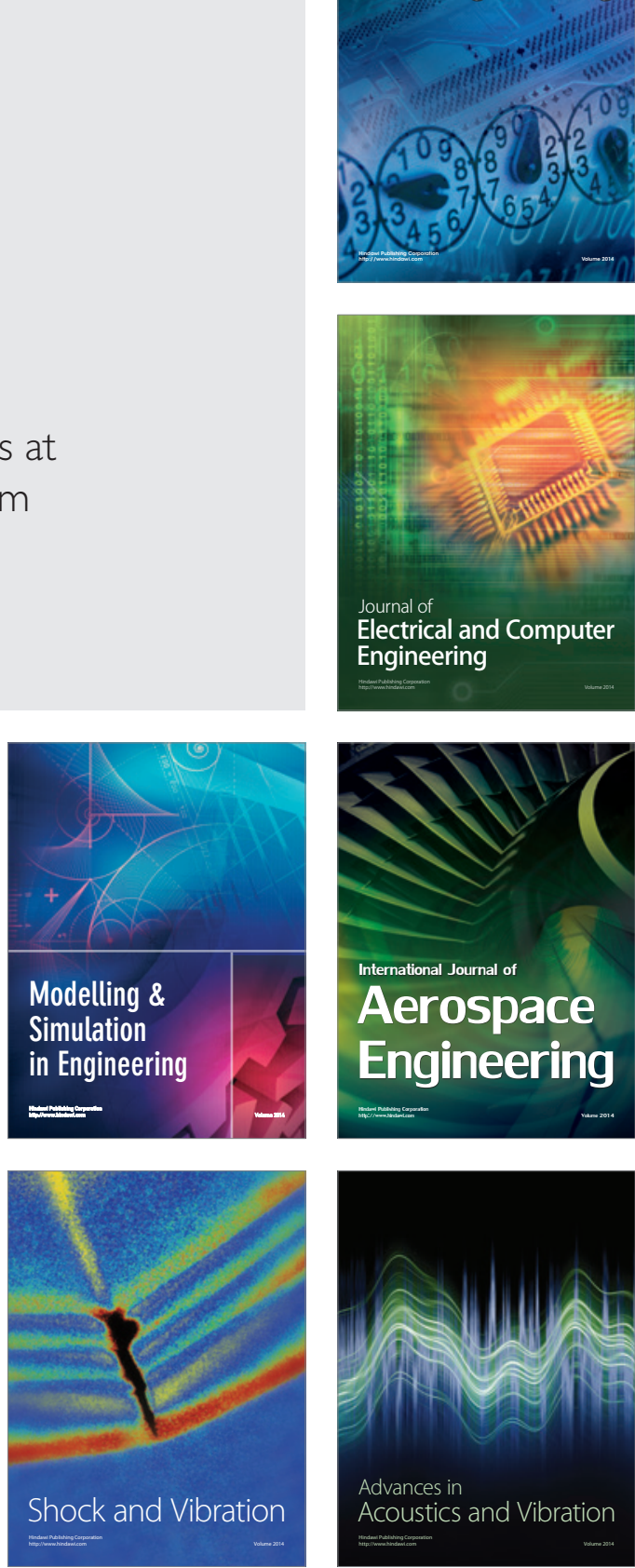